CEP Discussion Paper No 812

July 2007

The Effect of Information and Communication Technologies on Urban Structure

Yannis M. Ioannides, Henry G. Overman, Esteban Rossi-Hansberg and Kurt Schmidheiny 


\begin{abstract}
The geographic concentration of economic activity occurs because transport costs for goods, people and ideas give individuals and organisations incentives to locate close to each other. Historically, all of these costs have been falling. Such changes could lead us to predict the death of distance. This paper is concerned with one aspect of this prediction: the impact that less costly communication and transmission of information might have on cities and the urban structure. We develop a model which suggests that improvements in ICT will increase the dispersion of economic activity across cities making city sizes more uniform. We test this prediction using cross country data and find empirical support for this conclusion.
\end{abstract}

Keywords: ICT, urban structure, cross country data

JEL Classifications: O3, R1

Data: City Population project (http://www.citypopulation.de); World Bank World Development Indicators (online); International Road Federation World Road Statistics

This paper was produced as part of the Centre's Globalisation Programme. The Centre for Economic Performance is financed by the Economic and Social Research Council.

\title{
Acknowledgements
}

Thanks go to Kwok Song Too for data, and to Filipe Lage de Sousa, Kay Shan and Stefanie Sieber for research assistance. Comments by Marcus Berliant, Antonio Ciccone, Anna Hardman, Vernon Henderson, Soks Kim, Jed Kolko, Diego Puga, Will Strange and Ping Wang and other participants at presentations at Athens University of Economics and Business, University of Helsinki, University College London, Washington University in Saint Louis, Universitat Pompeu Fabra and the International Workshop on "Agglomeration and Growth in Knowledge-based Societies" are gratefully acknowledged. Last but not least, Philippe Martin made unusually generous and very perceptive comments on all aspects of the paper.

Yannis M. Ioannides is a Professor in the Economics Department at Tufts University, USA. Henry G. Overman is Deputy Director of the Globalisation Programme at the Centre for Economic Performance and Reader in Economic Geography in the Department of Geography and Environment, London School of Economics. Esteban Rossi-Hansberg is a Professor in the Economics Department at Princeton University, USA. Kurt Schmidheiny is an Assistant Professor in the Economics Department at Universitat Pompeu Fabra, Spain.

Published by

Centre for Economic Performance

London School of Economics and Political Science

Houghton Street

London WC2A 2AE

All rights reserved. No part of this publication may be reproduced, stored in a retrieval system or transmitted in any form or by any means without the prior permission in writing of the publisher nor be issued to the public or circulated in any form other than that in which it is published.

Requests for permission to reproduce any article or part of the Working Paper should be sent to the editor at the above address.

(C) Y. M. Ioannides, H. G. Overman, E. Rossi-Hansberg and K. Schmidheiny, submitted 2007

ISBN 9780853280255 


\section{The Effect of Information and Communication Technologies on Urban Structure}

Yannis M. loannides, Henry G. Overman,

Esteban Rossi-Hansberg, and Kurt Schmidheiny

\section{Introduction}

The geographic concentration of economic activity occurs because transport costs for goods, people and ideas give individuals and organisations incentives to locate close to each other. If such costs did not exist, then economic activity would tend to spread evenly over space. Historically, all of these transport costs have been falling. For example, steam, the railways, the combustion engine and the use of containers for transportation have all worked to reduce the cost of shipping goods, while the automobile, commuter railways 
and the airplane have performed a similar role for the cost of moving people. More recently, new information and communication technologies (ICT) have also significantly reduced the cost of transmitting and communicating information over both long and short distances. Such changes could lead us to predict the death of distance. That is, to suggest that location will no longer matter and that economic activity will, in the near future, be evenly distributed across space. This paper is concerned with one particular aspect of this prediction: the impact that less costly communication and transmission of information might have on cities, the urban structure and the spatial distribution of economic activity.

Two innovations in the last century have changed dramatically the cost of communicating and transmitting information. The first is the widespread adoption of telephony (first fixed line, then mobile), which made possible oral communication over long distances. The second main innovation is the internet and E-mail which has played a similar role for written documents, voice and images. Both these technologies may require substantial upfront fixed investments, but once made they essentially eliminate the link between the cost of communication and the distance between locations.

What are the implications of these changes in ICT for urban structure and the distribution of economic activity in space? This paper provides a partial answer to this question. We begin with a brief description of the adoption path for a number of recent ICT innovations before turning to consider in more detail the ways in which ICT might affect urban structure. We next present a formal model which helps clarify our thinking. Our model suggests that improvements in ICT will increase the dispersion of economic activity across cities. That is, it will make city sizes more uniform. In the empirical section, we test this prediction using cross country data and find empirical support for this conclusion. A concluding section spells out a number of policy implications.

\section{ICT and urban structure}

Changes in ICT are very clear in the data, especially if we focus on technology adoption. Figure 1 presents the number of cars, phone lines, mobile phones, and personal computers during the last five decades, using Comin and Hobijin's "Historical Cross-Country Technological Adoption Dataset" [Comin and Hobijin (2004)]. The adoption of the telephone was well under way by the 1950's. By the end of the 1990's, the number of telephone lines exceeds 150 million in both Europe and the US. In contrast, changes in personal computers are all concentrated in the 1980's and 1990's. The US went from less than 5 million computers in the early 1980's to more than 140 million computers in the late 1990's. This is a remarkable change that is likely to have very important effects. The data show a similar pattern for the EU that went from less than 5 million personal computers to 100 million in the late 1990's. The EU and the US have also experienced similar dramatic changes in the use of cell phones, but with the growth occurring even later than for personal computers. Mobile telephones technology was practically unused in 1985, but more than 150 million people owned a mobile phone in the 1990's in the EU, and more than 85 million in the US. Of course, these numbers alone do not reflect the costs associated with implementation of these technologies but they do show the dramatic growth in adoption. In particu- 


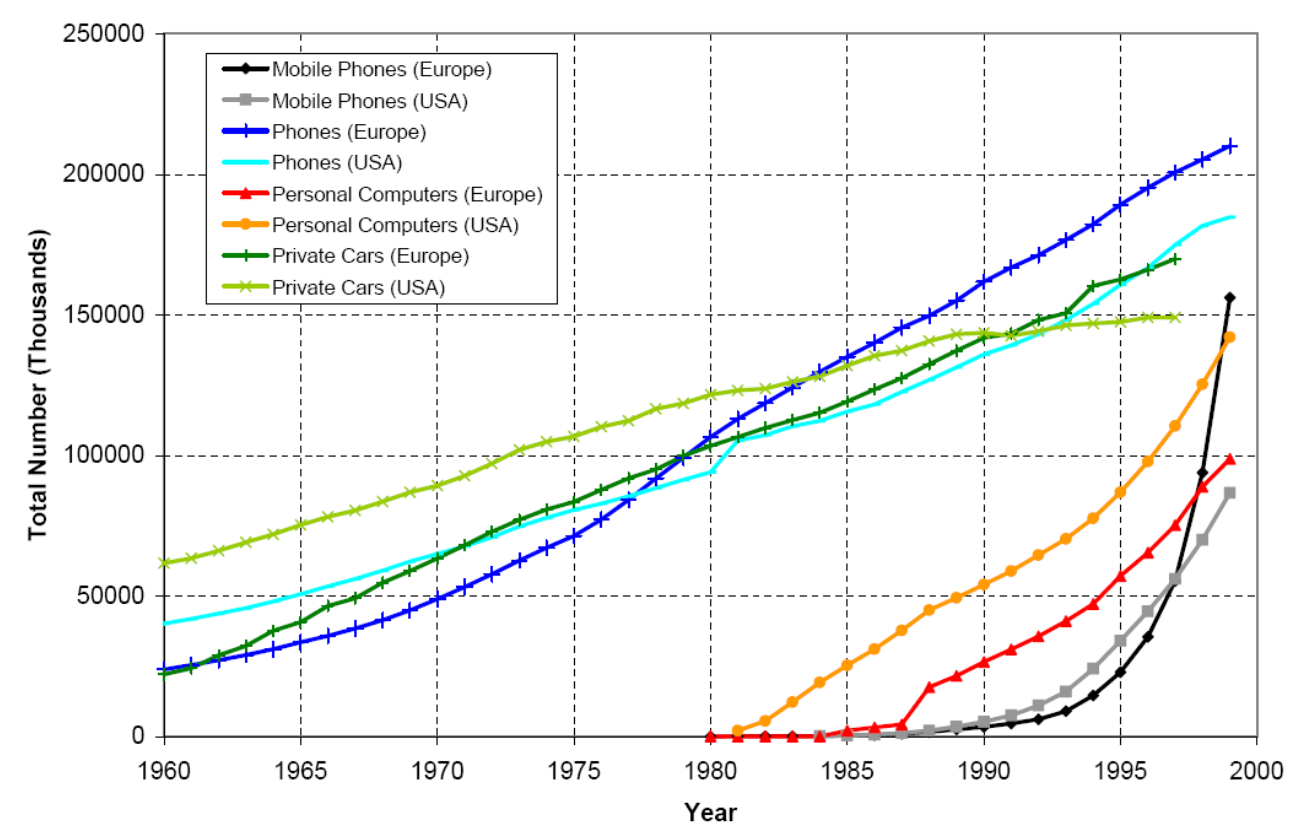

Figure 1. Private Cars, Mobile Phones and Personal Computers. Source: Comin and Hobijin (2004).

lar, contrast the linear growth in number of cars or phones with the exponential growth in new forms of ICT. If part of the role of cities is to save on communication costs, and given that this dramatic growth in adoption has clearly lowered these costs, it seems intuitive that these changes could have some significant implications for urban structure. It is to these implications that we now turn.

Economists use the phrase agglomeration economies to describe the advantages that occur when economic activity is densely concentrated. The first source of agglomeration economies is known as human capital or knowledge spillovers. In areas of dense economic activity, workers casually exchange knowledge about technology and production conditions at their places of employment. Such transfers happen fortuitously but also are sometimes sought out deliberately by firms, as anecdotal evidence about life in California's Silicon Valley testifies. A second force for agglomeration is labour market pooling. At any point in time, firms are subject to idiosyncratic shocks (e.g. as a result of changing demand for their particular product) that makes them want to hire or fire workers. Because these shocks are idiosyncratic, when one firm is firing, another firm may well be hiring. If firms locate together, it is easy for workers to move from firms experiencing bad times to those experiencing good times. As the saying in Silicon Valley goes, "people change jobs but not parking lots." Agglomeration is thus attractive to workers because it insures them against idiosyncratic shocks. It is also attractive for firms because it dampens down the response of wages to their own idiosyncratic shock. This actually makes employment more costly than it would otherwise have been in bad times, but this is more than compensated for by the ease of expansion in good times. A third force for agglomeration comes from 
the greater variety of intermediate products and richer mix of labour skills and expertise that are available in larger urban areas. Greater variety of goods and services lowers prices and wages and also enhances firms' options in choosing technologies for production and distribution of their products. The associated effects on firms are known as pecuniary externalities (as distinct from real externalities, the latter term being reserved for non-market interactions among economic agents' output decisions). Finally, local amenities due to weather, physical attractiveness, culture or tradition are an important factor in enhancing the appeal of particular urban agglomerations. These mechanisms, which essentially go back to Alfred Marshall's Principles of Economics, explain at least some of the spatial concentration that we observe throughout the world.

Of course, if these agglomeration economies were the only forces driving the location of economic activity then we would expect to observe extreme spatial concentration. In reality, we do not, because these agglomeration economies are offset by costs (dispersion or congestion forces) as activity becomes increasingly concentrated. These costs take many forms but all arise from the fact that competition for local resources, broadly defined, increases with spatial concentration. For example, congestion occurs as a result of increased competition for space, firms pay higher rents and wages as result of increased competition for land and workers, while they receive lower prices for their output as a result of increased competition in goods markets. The balance between these agglomeration and dispersion forces determines the spatial structure of the economy.

The strength and importance of these agglomeration and dispersion forces depend on many things, including the cost of communicating information across space. Knowledge spillovers, for example, depend on the role that distance plays in inhibiting efficient communication of ideas. The importance of face to face communication shows just how dramatic can be these distance effects. But the telephone, the email and video conferencing, for example, are all reducing these costs of communicating ideas at a distance.

Changing communication costs may also affect the benefits from labour market pooling. Remember, these benefits require works to move from firm to firm. ICT may increase the efficiency of this process as news about vacancies in one firm are more easily communicated to workers who may be looking for work. A similar story could be told about the benefits of pecuniary externalities. For example, falling information costs allow firms to more easily identify potential suppliers of intermediate goods or skills. Turning to dispersions forces, ICT may facilitate e-working, allowing individuals to avoid the high costs of commuting in congested cities. Alternatively, it may increase the competition faced by firms as consumers find it easier to identify alternative sources of supply.

Thus, new ways to transport ideas and communicate information are, in general, likely to affect all of the agglomeration and dispersion forces that urban and regional economists have identified as key determinants of the concentration of economic activity in space. Thus, independently of the sources of agglomeration forces, ICT will likely have an impact on spatial concentration. In what follows, we illustrate the potential impact of ICT by focusing on production externalities as the main source of agglomeration. This gives us a prediction about the impact of ICT that we then confirm using real world data. These effects may also be consistent with other models where ICT has a similar effect on different 
agglomeration economies. So, our exercise does not allow us to discriminate between different models which predict that ICT will disperse economic activity across cities. It does, however, suggest that models that predict the opposite changes to city structure (i.e. increasing concentration) are not consistent with the data.

ICT can, in principle, have many distinct effects on the distribution of economic activity in space. On one hand, it can increase the spatial scope of knowledge spillovers -it is easier for any professional to acquire context that helps her assess information she casually receives from counterparts in other firms. Therefore, fewer person-to-person interactions may suffice to obtain a better understanding of what other firms are up to. To the extent that knowledge spillovers, whether deliberate (as among employees of the same firm) or fortuitous, are productive, we would expect that ITC would make them more effective among individuals who are located further apart. Local increasing returns are thus less localized when a wider set of people across a whole country or across countries can interact with each other by using new technologies and while economizing on commuting costs. In this sense, improvements in ICT reduce the importance of the quantities of productive factors employed in a city on that city's productivity. This is the stand we take on the theory we present in the next section.

This implies that local urban agglomeration effects become less important and lead to less concentration of people and jobs in a few successful (and larger cities) or urban agglomerations. Agents and firms obtain smaller benefits from locating close to each other and so they locate more evenly in space in order to economize on land rents (and other congestion costs). ICT, in particular, can help businesses create opportunities by improving their communications with other firms, suppliers and clients worldwide. For example, real estate, tourism and hotel operators may market their products directly, without relying on city-based intermediaries. This is important, as most of recent urban growth worldwide has been fuelled by growth in service sectors, while manufacturing has been relocating to smaller urban centres with good transportation links [Henderson (1997)] and often outsourced to lower cost countries.

These arguments associate ICT with greater dispersion in economic activity. This would, in turn, imply larger concentration of the city size distribution. That is, it would be associated with a reduction in the variance of city sizes. Arguably, this potential advantage may not be fully realized if the interurban transportation system does not develop sufficiently to serve a greater network of urban centres. However, at any given level of development, improvements in ICT increase the incentives for economic activity to relocate to smaller urban centres.

On the other hand, ICT may also make certain local public goods more important as a share of consumption or as a share of inputs. Also, changes in the industrial composition of cities, which have been favouring services, may on balance foster concentration of certain services due to increasing returns at the plant level. London, New York or Paris are attractive in part because there are certain products and services that can only be found there. Similarly, urban living affords better consumption prospects. As individuals spend more on amenities, such as theatres and other artistic activities, certain large cities would become relatively more attractive and therefore likely to grow relative to smaller or me- 
dium cities. On top of increasing the share of some of these goods and services in consumption, better ICT may make these goods and services more readily available and cheaper to consume. Clearly, to the extent that public goods (and other forces of urban concentration) become effective and far reaching with ICT, we should observe a more dispersed distribution of cities and a more concentrated distribution of economic activity.

From this verbal discussion it should be clear that there are two key paths through which ICT may affect the urban structure. But it is still not clear which effect is likely to dominate. Our next step is thus to develop a theoretical model which will make all these connections clear. In particular, it will connect changes in ICT with changes in the size distribution of cities. As we will show, the effect on urban structure generated by the model will depend on the particular assumption made on how ICT affects agglomeration forces. This relationship is monotonic and so it helps us design an empirical exercise that is informative on which of these different effects dominates in reality.

\section{A Model of ICT and Urban Evolution}

As discussed above, any reasonable model of urban structure or of the role of space in economic activity, more generally, would predict that improvements in ICT should have effects on the distribution of economic activity in space. However, no model of urban systems seems to have explicitly incorporated the effects of ICT. We use the theory in RossiHansberg and Wright (2007), from now on RHW, to illustrate how ICT may lead to more urban dispersion. As one may see in more detail in Appendix A, this is a dynamic model that allows for investment in both physical and human capital and yields very specific results about the properties of an urban economy in the long run. We incorporate ICT as a determinant of the agglomeration forces that drive productivity for each industry in each city. Each industry is assumed to be served by several cities and cities specialize completely. Therefore, changes in ICT can influence the typical sizes of cities specialized in an industry, which in turn will determine the concentration of economic activity is space.

To reiterate, the trade-off between agglomeration effects - the benefits that firms and individuals obtain from being close to each other- and congestion costs determines the size of cities. Most of these agglomeration effects are related to interactions of different types among individuals. These interactions will be affected by the communication and information technology used by these agents. But how will ICT affect agglomeration forces? And how will these changes in agglomeration forces change the distribution of economic activity in space?

The potential effect of ICT on the dispersion of the size distribution of cities is not obvious. Essentially, we need to understand whether the consequences of productivity shocks, or of other shocks that cities may experience, will be more or less persistent, and will have larger or smaller effects, the larger agglomeration forces. The model in RHW views the connection between agglomeration effects and productivity as mediated by industry specific physical and human capital. Agglomeration effects are the result of an externality generated by the amount of human capital and labour employed in the city. 
To illustrate this mechanism, suppose that an industry receives a positive and persistent productivity shock. Naturally, firms in the cities that produce in those industries will want to produce more. This implies that they want to use more of the industry specific factors. But the total availability of those factors is given in the current period. So the price of the industry specific physical and human capital increases. The positive productivity shock also implies that cities specialized in that industry will grow as firms employ more workers. The higher price of the industry specific human and physical capital will create incentives to accumulate more of these factors. So next period the industry will have more industry specific factors. Because of the agglomeration effects (and this is the key) having more of these factors will imply more workers being hired and higher productivity, which in turn will elicit further accumulation of factors and induce larger cities, even if next period's productivity shock is lower. That is, the effect of the original productivity shock on city size will be persistent through its effect on the accumulation of industry specific factors. The stocks of these factors are determined by the accumulated history of the industry's productivity shocks and, therefore, the size distribution of cities is determined by the history of these shocks. It is the distribution of these factors across industries which then determines the size distribution of cities.

The mechanism described above relies crucially on the impact that the level of human and physical capital has on the level of productivity in a city - that is, on the strength of the agglomeration effects. The stronger these effects, the larger the impact of past productivity and the larger the reaction of city size and industry specific factors to an idiosyncratic productivity shock. If agglomeration forces are very small and the productivity of an industry producing in a given city is essentially independent of the level of human capital and employment in the city (and therefore the level of physical capital), today's productivity shock will have only a temporary effect on city size and no effect on the long term stock of these factors. Hence, cities will not grow and may even decline substantially depending on the history of shocks to an industry. This implies that all cities will have similar sizes and so the distribution of city sizes will be extremely concentrated. If all cities are of similar sizes, the distribution of economic activity in space will exhibit a lot of dispersion. Note that the more concentrated the size distribution of cities the more dispersed the distribution of economic activity in space.

In contrast, if agglomeration effects depend heavily on the amount of factors employed in a city, the effect of past shocks on the stock of industry specific factors will be very important. Cities specialized in industries that received a history of good shocks will be very large, and cities that received a history of bad shocks will be small. Hence, the size distribution of cities will be very dispersed and the distribution of economic activity in space will be very concentrated.

Our focus then is on the effect that ICT has on the relationship between the levels of human capital and employment in a city and the productivity of firms operating in that city. If improvements in ICT decreases the externality generated by human capital and employment in an industry it will lead to a more concentrated distribution of city sizes and more dispersion in the distribution of economic activity in space. If the reverse is true, so that improvements in ICT lead to larger externalities from employment and human 
capital, we should observe a more dispersed distribution of cities and a more concentrated distribution of economic activity in space. The model in RHW helps us link the effect of changes in ICT on urban agglomeration forces with the dispersion —or more precisely the variance- of the distribution of city sizes.

We now present more details of the formal model in RHW (all derivations are relegated to Appendix A). Our choice of model is influenced by the fact that this framework allows for several important productivity effects in a dynamic setting that are key elements of the economic phenomena we wish to address. First, it allows for an industry-specific technology shock for each industry over and above all variable inputs which may vary over time. This industry specific total factor productivity growth implies that output increases even while input quantities are constant. Second, it contains spillover effects in urban production that are specific to each city. And third, it includes commuting costs which themselves may be affected by technological improvements. It follows Henderson (1974) in some of its features and proposes a theory of the size distribution of cities where the size of a city is determined by the city's core industry (cities specialize), the amount of industry specific human and physical capital, production externalities in labour and human capital, and commuting costs. Each industry's technology, that is its total factor productivity, is defined as a weighted geometric mean of the industry's total employment and industry-specific human capital in the city, and an additional factor that is random and is an independent and identically distributed (i.i.d.) productivity shock with constant mean and variance.

We measure the importance of knowledge spillovers from total industry employment via the elasticity $\gamma_{j}$ and from industry specific human capital in the economy via the elasticity $\varepsilon_{j}$. These elasticities depend on the weight each receives in the determination of industry $j$ total factor productivity. These parameters are external to individual firms in the industry (that is, beyond those firms' control), but internal to the urban economy due to the presence of city developers. City developers arbitrage across city sizes.

Ideally one would model explicitly the decision of agents in a city to adopt ICT. This has not been done in the literature in a way that may be readily adopted for our purposes. Here we only study the effect on urban structure given exogenous technology adoption decisions. A very simple way to introduce the effect of ICT is to let those two elasticities vary with the quality of information technology, $ı$. The nature of the dependence represents two alternative effects of ICT. We may assume that ICT weakens the importance of agglomeration effects, if the parameters $\gamma_{j}\left(l_{t}\right)$ and $\varepsilon_{j}\left(l_{t}\right)$ decrease as ICT improves. Since people located far away can now interact at a smaller cost, and thus people do not have to be close together to be productive, agglomeration effects attenuate at a slower rate with distance, and so people living in a city are less important in determining that city's productivity level. Conversely, assuming that both $\gamma_{j}\left(l_{t}\right)$ and $\varepsilon_{j}\left(l_{t}\right)$ increase with the quality of ICT would be consistent with a greater importance of city specific factors (like public goods) as a result of changes in ICT. In such a case, the larger both of these parameters the more important are a city's total human capital and employment in determining city-specific total factor productivity for industry $j$. Which effect dominates is, ultimately, an empirical question that we try to settle in this paper. 
In modelling an economy's urban structure, the theory recognizes an important tradeoff that is generated by city geometry. Cities consist of a central business district, where all agents work and all production is located, and residential areas surrounding it. Each agent consumes the services of one unit of land per period. In a spatial equilibrium within each city, agents should be indifferent over where to live. Therefore, equilibrium rents should vary with location so as to compensate agents for increased commuting costs, with rents at the city edge assumed to be equal to zero. In the model these costs per person increase with city population capturing increasing congestion. On the other hand, any given amount of employment and human capital in a city is not only directly productive, but also indirectly through the spillover effects.

With a given national population, as the number of cities varies, the total congestion costs and the output of the city's industry, which reflects both effects of employment and human capital, change at different rates. Therefore, a trade-off emerges which, with a given national population, implies a specific number of cities. Cities exhibit optimal sizes as city developers internalize the external effects at the city level. Since the knowledge spillovers are city- and industry-specific, it pays for cities to specialize. That is, a city's silk industry should not be burdened by extra congestion costs imposed by a semiconductors industry and the developer ensures that this is the case.

The process of city formation resembles free entry equilibrium in the textbook case of an industry with firms that have U-shaped cost curves. In equilibrium, with free entry, all cities produce at the average cost minimizing quantity of output and the industry is served by an appropriate number of cities. Thus, aggregate industry output effectively exhibits constant returns to scale. RHW attribute urban growth to the outcome of the trade-off between commuting costs and knowledge spillovers, which reconciles increasing returns to scale at the local level and constant returns to scale at the aggregate level.

Given this log-linear specification, RHW show (see Appendix A) that the variance of city sizes for each industry is given by

$$
V_{0}\left[\ln s_{t j}\right]=4 v\left(\left(\frac{1}{1-2\left(\gamma_{j}+\varepsilon_{j}\right)}\right)^{2}+\left(\frac{\beta_{j}}{1-2\left(\gamma_{j}+\varepsilon_{j}\right)+\beta_{j}}\right)^{2}\right) .
$$

where $\ln s_{t j}$ is the size of cities specialized in industry $\mathrm{j}$ at time $\mathrm{t}$, and $\beta_{j}$ is the capital share in production. Note from Equation (1) that the variance of the city size distribution is increasing in the sum of the elasticities of the spillover effects, $\gamma_{j}\left(\mathbf{l}_{t}\right)+\varepsilon_{j}\left(\mathbf{l}_{t}\right)$. So if these elasticity parameters depend negatively on the quality of ICT, the variance is decreasing in $\boldsymbol{l}_{t}$, or decreases as ICT improves. Or, put differently, ICT makes the city size distribution more concentrated, or the distribution of economic activity in space more dispersed.

In the previous paragraph we have taken the stand that improvements in ICT reduce $\gamma_{j}\left(\mathrm{l}_{t}\right)+\varepsilon_{j}\left(\mathrm{l}_{t}\right)$. However, if better ICT increases the importance of public good or increases agglomeration forces in general, then $\gamma_{j}\left(\mathbf{l}_{t}\right)+\varepsilon_{j}\left(\mathbf{l}_{t}\right)$ would increase with improvements in ICT. Public goods and other forces would increase local spillover effects and therefore would lead to exactly the opposite effects than the ones derived above: A 
less concentrated size distribution of cities and a more concentrated distribution of economic activity. The data can potentially help us distinguish the role played by changes in the quality of ICT on urban structure, and through the theory, the effect of better ICT on the elasticity of technology to urban factors. In the next section we turn to study this relationship empirically.

The model above incorporates ICT only in reduced form. One could also go deeper into the specification of the spillover functions $\gamma_{j}\left(l_{t}\right)$, and $\varepsilon_{j}\left(l_{t}\right)$ by trying to model the effect of lower communication costs on total factor productivity. We refrain from doing so because it is unlikely that in view of our data we would be able to distinguish between alternative theories of the precise role of ICT in affecting the elasticities of the spillover effects.

Finally, one can also incorporate the impact of ICT on commuting costs (as in the notable increase in the use of personal vehicles documented above, or because of telecommuting) by letting commuting costs depend on ICT. The effect of ICT on commuting costs affects city growth rates independently of their scale. As shown in Appendix A, lower commuting costs as a result of improvements in ICT result in all cities' growing at a faster rate. Thus, declining commuting costs change the mean of the distribution of city sizes but not its shape or variance. As the prediction concerning the variance is the one we take to the data this justifies our focus in the preceding discussion of the model.

\section{Empirical Methodology}

Our theoretical model predicts that ICT should make the distribution of city sizes in the long run more concentrated if it weakens agglomeration effects. We study this prediction empirically by looking at the effect of ICT on the distribution of city sizes across different countries.

Unfortunately, as will be clear when we discuss our data in Section 5 below, the available data only tend to cover the larger cities in each country. This is a problem for our empirical implementation because such truncated data (i.e. data that do not cover the smaller cities) do not allow us to calculate the mean and variance of the entire city size distribution directly. To get around this problem, we proceed as follows. First, we assume that the city size distribution is Pareto (alternatively referred to as following a power law). Given this assumption we can express the log of the proportion of cities that are larger than $S$, that is the $\log$ of the counter-cumulative of the size distribution of cities, as a linear function of $\log$ city size:

$\ln P(s>S)=-\zeta \ln S_{o}+\zeta \ln S$,

where $S_{o}$ denotes the minimum city size and $\zeta$ the elasticity of the proportion of cities larger than $S$ with respect to $S$, a negative number that is commonly referred to as the Zipf coefficient. See Box 1 for details. Given a set of cities, an estimate of the Zipf coefficient is provided by running a regression of log rank on log city size. How does this help us? First, because when the distribution is Pareto the Zipf coefficient can be consistently estimated by running the regression only on the largest (i.e. truncated) sample of cities. Sec- 


\section{BOX 1: Zipf's law and the Pareto distribution}

Zipf's law for cities [Zipf (1949)] is an empirical regularity that has attracted considerable interest by researchers. In its strict version, which is also known as the rank-size rule, the law is a deterministic rule that states that the second largest city is half the size of the largest, the third largest city is a third of the size of the largest city, etc. To illustrate, let us take a country (for instance the US), and order its cities by population: New York as the largest has rank 1, Los Angeles as the second largest has rank 2, etc. We then draw a graph, known as Zipf's plot (see Fig. B.1): on the $y$-axis, we place the log of the rank (New York has log rank $\ln 1$, Los Angeles $\log$ rank $\ln 2$ ); on the $x$-axis, the $\log$ of the population of the corresponding city (which will be called the size of the city). If the rank-size rule holds, this produces a downwards sloping line with slope equal to -1.

Generally, and to a remarkable extent, statistical analyses for many different countries, as Gabaix and Ioannides (2004) discuss in detail, obtain estimated coefficients that are concentrated often around one. This indicates that the size distribution of cities is well approximated by Zipf's law with coefficient one. Nevertheless, there is substantial variation in Zipf's coefficients across time and across countries, a fact that ought to cause some doubts as to full validity of the law.

Consider the three Zipf plots on Fig. B.1. They look quite similar to one another, yet the slopes of ordinary least squares lines fitted to them are not equal to -1 . Note that the plot for France is steeper than that for UK which in turn is steeper than that of the US; the respective estimates are $-1.55,-1.46$, and -1.37 , are all estimated with very high precision and using 96, 232 and 552 observations, respectively. Note also that the plot for the US is furthest to the right because its cities are larger than those of the UK with the same rank, whose plot in turn is further out than that of France, for the same reason. The techniques employed in the main part of the paper are aimed at backing out from such differences the effect of ICT across countries and over time.

Can we obtain Zipf's law by means of theoretical arguments? The simplest direct theoretical argument one could make would be by invoking Gibrat's law. If different cities grow randomly with the same expected growth rate and the same variance (Gibrat's Law for means and variances of growth rate), then the limit distribution of city sizes converges to Zipf 's law. See Gabaix and Ioannides (2004) for an extensive discussion of this issue. Empirically, on the other hand, Zipf's law for cities is an instance of a power law (see further below for details). Power laws are attractive in various sciences, especially in physics, because they are "scale free", in that they do not depend on the definitions of units of measurement. Naturally, this is an important concern in physics. RossiHansberg and Wright (2007) provide a rigorous justification for a power law that is directly rooted in economic theory. It follows as a special case of the model outlined in Appendix A.

A power law of cities states that the proportion of cities that are greater than a particular city of size $S$, the counter-cumulative of the size distribution of cities, is of the form: 


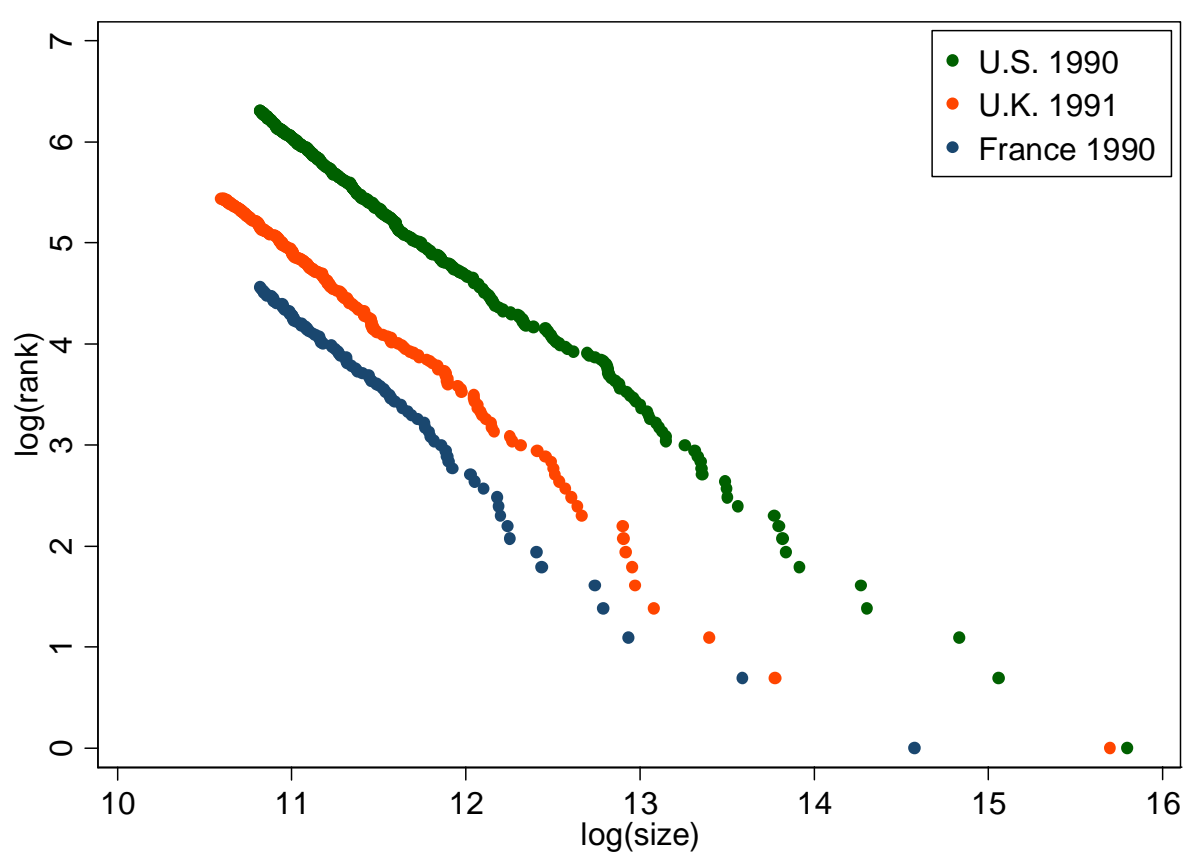

Figure B.1. Zipf's plots for three countries. Source: Authors' own calculations.

$$
P(s>S)=\left(\frac{S}{S_{o}}\right)^{\zeta},
$$

where $\zeta$ denotes a negative parameter, and $S_{o}$ the lower boundary of the distribution, also a parameter and itself a function of the various determinants of city sizes as discussed in the main body of the paper and Appendix A. The mean city size and the variance associated with the law given by Equation (B.1), which is also known as a Pareto probability distribution, are given by:

$$
\bar{S}=E\{S\}=\frac{\zeta}{\zeta+1} S_{o} ; \quad V_{0}\{S\}=\frac{\zeta}{(\zeta+1)^{2}(\zeta+2)} S_{o}^{2} .
$$

The mean is finite, if $|\zeta|>1$; the variance is finite, if $|\zeta|>2$. Zipf's law is the case of a Pareto law with $\zeta=-1$. These properties also help underscore that the rank-size rule cannot correspond to a reasonable probability distribution, strictly speaking, as such a distribution would have neither a finite mean nor a finite variance.

With these caveats, it is still interesting to note that with our data, reasonable good statistical fits are obtained when we regress the log rank against log city size and a constant, which is the so-called Zipf regression. Interestingly, for all country-year pairs we strongly reject the null hypothesis that the Zipf coefficient is equal to minus one. In other words, we strongly reject Zipf's law, strictly construed.

"Every cloud has a silver lining," however. Starting from an empirical law, like Zipf's law, one may motivate a more general and far reaching inquiry into urban structure and growth and therefore on the determinants of city size distributions. This is what we have sought to do in this paper! 
We think that rigorous research along the lines of our paper helps caution economists, sociologists, urban scientists and econophysicists against undue predictions. E.g., as groups of countries integrate, like the EU, economic forces are unleashed which reshape their urban systems. What is likely to happen to the sizes of their larger cities and their ranks? Zipf's law offers a straightforward prediction. But is it reliable? We think not, and have instead proposed a way to make predictions that rely on underlying determinants of city sizes in a dynamic world.

ond, because for a Pareto distribution changes in the Zipf coefficient map one to one to changes in the variance of the city size distribution.

We have underscored the model's prediction that improvements in ICT will decrease the variance of the cross-sectional distribution of cities. In Appendix A we show that this leads to a higher absolute value of the Zipf coefficient, $|\zeta(S)|$. Hence, the absolute value of the Zipf coefficient increases with improvements in ICT, at least when attention is restricted to the upper tail of city sizes. In other words, improvements in the quality of ICT decrease the variance of the size distribution while they increase the absolute value of the Zipf coefficient. Since the Zipf coefficient is negative, they decrease its algebraic value. This result holds independently of whether the size distribution is Pareto. Of course, if it is not Pareto, the Zipf coefficient will not be a constant, but the model predicts that its value will change in the same direction for all, large enough, city sizes. It is important to note that even though the theory in the previous section implies a Pareto distribution of city sizes only for particular cases (see RHW for details), we approach the data using Zipf coefficients that are specified as independent of city size. That is, we assume that the size distribution is always Pareto.

So our assumption of a particular distribution for city sizes gives us a specification that can be estimated given the data that we have at our disposal and that allows us to directly test our theory on the impact of ICT on the city size distribution. The crucial question is then, of course, whether this is an appropriate assumption. It turns out that empirical evidence give us good reason to think that the Pareto distribution is a reasonable fit for real world city size distributions across a large numbers of countries and at many different points in time. Even if the distribution is not Pareto, it is likely that reductions in variance will be associated with the same direction of change for the Zipf coefficient (as discussed above). In the empirical section, we also address this concern by presenting robustness checks using other measures of dispersion in the upper tail.

Once we have the estimated Zipf coefficient, we may use it as a summary of the city size distribution for different countries and examine how variations in the city size distribution may be attributed to the observed changes in ICT. Clearly a large number of other factors will determine the city size distribution and we will need to control for these if we want to isolate the effect of ICT. We discuss and motivate these additional controls in the results section below.

To capture the effects of ICT we use data on the number of telephone lines and on access to the internet. Our main focus is on the number of telephone lines for several rea- 
sons. First, because we have more data. Second, because the impact on the urban structure will take time and, as Figure 1 shows, the rapid adoption of internet technology has only occurred relatively recently. Third, because for telephone lines we have a way to deal with the endogeneity problem for ICT. That is, we have a way to control for the fact that the number of telephone lines or internet connections may be driven by the urban structure, rather than the other way round. To allow for this, we need to find a suitable instrumental variable that is correlated with the number of telephone lines, does not independently affect the urban structure and is unlikely to be affected by changes to that urban structure. Information on the industrial organization of telecommunications sector provides such a variable because it is related to the number of telephone lines, but should not independently affect urban concentration. We believe this is a natural way to proceed, since it is hard to argue that urban concentration directly influences the competition status of the telecommunication sector in a country or vice versa. As no such instrumental variable is available for the internet, our results there are necessarily more speculative (although both sets of results point in the same direction).

The Zipf coefficient for a country $c$ in year $t$ is obtained from the following regression:

$$
R_{i c t}=\lambda_{c t}+\zeta_{c t} P_{i c t}+e_{i c t},
$$

where $R_{i c t}=\ln \left(\operatorname{rank}_{\text {ict }}\right)$ is the $\log$ of the rank of city $i$ in country $c$ in year $t, P_{i c t}$ is the $\log$ population of that city, $\lambda_{c t}$ is a country-year specific intercept, and $\zeta_{c t}$ is a countryyear specific Zipf coefficient.

To analyze what factors explain the city size distribution Rosen and Resnick (1980), with that work subsequently having been updated by Soo (2005), take the estimated Zipf coefficients $\zeta_{c t}$ from a regression like (3) and seek to understand its determinants in terms of generally time-varying country-level characteristics. This is accomplished by means of a (so-called second step) regression of the estimated Zipf coefficients for each country and year, $\hat{\zeta}_{c t}$, against $X_{c t}$, a collection of explanatory variables that are thought to determine the city size distribution. That is:

$$
\hat{\zeta}_{c t}=\theta+X_{c t} \eta+\varepsilon_{c t},
$$

where $\theta$ is a constant and $\eta$ is a vector of coefficients. From among the explanatory variables we include telephones per capita, density of roads, volatility of growth of GDP per capita and other variables.

We implement a similar approach, but make three modifications. The first deals with a potential bias in the estimation of the Zipf coefficient. The second increases the efficiency of the estimators by implementing a one-step procedure rather than the two-step procedure just described. The third exploits the fact that we have panel data and thus may control for unobserved country specific determinants of differences in the city size distribution. We describe each of these three modifications in turn.

In a recent paper, Gabaix and Ibragimov (2006) return to a known bias of the estimate of the Zipf coefficient from Equation (3). This bias arises from the fact that ranks and sizes are obviously correlated. The bias is strong in small samples and their proposed cor- 
rection is to use $R_{i c t}^{*}=\ln \left(\mathrm{rank}_{\text {ict }}-0.5\right)$ in place of the log rank in the left hand side of Equation (3). We implement that correction here and run a regression like (3),

$$
R_{i c t}^{*}=\lambda_{c t}+\zeta_{c t} P_{i c t}+e_{i c t} \text {, }
$$

where $P_{i c t}, \lambda_{c t}$ and $\zeta_{c t}$ are defined as before. Our second change is to recognise that instead of adopting the two-step procedure found in the existing literature, we can get more efficient estimators if we substitute for $\hat{\zeta}_{c t}$ from Equation (4) into equation (3) and estimate instead:

$$
R_{i c t}^{*}=\lambda_{c t}+\theta P_{i c t}+\left[X_{c t} P_{i c t}\right] \eta+e_{i c t}^{*},
$$

where $e_{i c t}^{*}$ is now composed of an i.i.d. error plus the interaction between rank and error from the first step, while all other coefficients and variables are as defined before.

Both the two-step and one-step procedures -Equations (3)-(4) and (5), respectivelycontrol for observable country characteristics that may affect the city size distribution. However, as we have ranks of cities and explanatory variables for several years, we can also control for unobserved country characteristics that may affect the distribution. Continuing to implement the Gabaix-Ibragimov we work with the following modification of Equation (6):

$$
R_{i c t}^{*}=\lambda_{c t}+\theta_{c} P_{i c t}+\left[X_{c t} P_{i c t}\right] \eta+e_{i c t}^{*} \text {. }
$$

The only difference from Equation (5) is that the $\log$ population of city $i$, country $c$, time $t$ is allowed to have an effect which is country specific, $\theta_{c}$. Of course, as one would expect, if $X_{c t}$ contains time invariant observed characteristics then their coefficients cannot be separately identified via econometric procedures that allow for unobservable country-specific effects.

Before turning to the implementation of our approach, we re-iterate that, although we rely on Zipf's law to motivate our econometric approach, our estimations should generally capture the impact upon the entire distribution of city sizes that emanate from changes in underlying determinants of interest.

\section{Data}

We use the same city data as that used in Soo (2005), which were taken from Thomas Brinkhoff's City Population project (http://www.citypopulation.de). Soo's paper provides a fairly extensive discussion of the nature of the data, particularly with regard to the issue of the definition of cities. ${ }^{1}$ Data on population, GDP per capita in 2000 Purchasing Power Parity (PPP), trade and government expenditure as a percentage of GDP, non-agricultural economic activity and land area come from the World Bank World Development Indicators (online). Data on kilometres of roads come from the International Road Federation

\footnotetext{
${ }^{1}$ We use data on cities as opposed to urban agglomerations because they are more consistently available internationally.
} 
World Road Statistics. ${ }^{2}$ GDP growth is calculated as log difference of GDP in 2000 PPP; its volatility is measured as the empirical standard deviation over the observed time period.

We use two different measures to evaluate the role of ICT in determining the city size distribution: telephones and the internet. As already discussed, our main focus is on telephones, because we have data for a longer time period. Data on the number of telephone land lines and internet users per 1000 also come from the World Bank World Development Indicators. We multiply these numbers by 1000 and use per capita measure of phone lines and internet users in the estimations.

We also use two sets of variables as instruments to purge two explanatory variables of their endogeneity. The first set, and the most crucial, provides information on the market structure of the telecommunications sector (private or public monopoly versus competitive provision) and is used to instrument the number of telephone lines. The telecommunications data are taken from the OECD International Regulation Database. ${ }^{3}$ We use these variables to instrument the number of phone lines, as discussed further below. A second set of variables are used to instrument for trade as a percentage of GDP and are derived from information on membership of the two most important regional preferential trade agreements for several of the countries that we consider, that is, the North American Free Trade Agreement (NAFTA) and the European Economic Community and the European Union, as appropriate in the respective years (EEC/EU). The membership variables were constructed by the authors based on the year in which countries joined the respective trading area. ${ }^{4}$

We start with city-level data for 73 countries covering 7,530 different cities recorded at various time periods between 1972 and 2001. There are 197 country-year pairs meaning that, on average, we observe each country 2.7 times. Detailed inspection of the data reveals that the relevant explanatory variables are missing for many countries. Fortunately, the variables are available for three blocks of countries -- North America, Europe and some of the former countries of the Soviet Union. ${ }^{5}$ Deleting countries with missing data

${ }^{2}$ Further details on all these variables are provided in Soo (2005). A large number of our explanatory variables were also kindly provided by Kwok Tong Soo.

${ }^{3}$ See the Indicators of Product Market Regulation Homepage at: http://www.oecd.org/eco/pmr and described in Conway (2006). Missing data points for Eastern European countries were filled by the authors based on media coverage.

${ }^{4}$ Other variables may also, of course, be endogenous, but these are the two for which we have been able to construct reasonable instruments.

${ }^{5}$ Specifically, we use data on Austria, Belarus, Belgium, Bulgaria, Canada, Denmark, Finland, France, Greece, Hungary, Italy, Mexico, the Netherlands, Norway, Poland, Portugal, Romania, the Russian Federation, the Slovak Republic, Spain, Sweden, Switzerland, the United Kingdom and the United States. We have to drop Germany because of the reunification of 1990 and the ensuing adoption of Federal Republic of Germany institutions in former German Democratic Republic territory causes definitional problems. 
Table 1: Descriptive statistics

\begin{tabular}{llllll}
\hline \hline & Mean & Std. Dev. & Min & Max & Obs \\
\hline City specific variables & & & & & \\
City size & 132,282 & 339,529 & 10,054 & $8,405,000$ & 6975 \\
Normalized city size & 0.0042 & 0.0105 & 0.0002 & 0.2024 & 6975 \\
$\quad$ log(norm. city size) & -6.31 & 1.25 & -8.64 & -1.60 & 6975 \\
Country specific variables & & & & & \\
Phone lines per capita & 0.402 & 0.178 & 0.065 & 0.722 & 63 \\
log(Phone lines per capita) & -1.043 & 0.574 & -2.736 & -0.326 & 63 \\
Inverse road density & 0.033 & 0.067 & 0.002 & 0.329 & 63 \\
Country population & $35,200,000$ & $57,400,000$ & $4,209,000$ & $282,000,000$ & 63 \\
log(country population) & 16.632 & 1.108 & 15.253 & 19.458 & 63 \\
GDP per capita, PPP & 18,287 & 7,838 & 4,369 & 33,970 & 63 \\
log(GDP per capita), PPP & 9.692 & 0.544 & 8.382 & 10.433 & 63 \\
Trade, \% GDP & 0.735 & 0.317 & 0.205 & 1.680 & 63 \\
Non-agric. sectors, \% GDP & 0.936 & 0.054 & 0.732 & 0.988 & 63 \\
Gov. expend., \% GDP ${ }^{\text {a }}$ & 0.378 & 0.082 & 0.161 & 0.490 & 63 \\
Std. dev. of GDP growth & 0.029 & 0.019 & 0.013 & 0.083 & 63 \\
land area & $1,612,057$ & $3,853,566$ & 30,230 & $16,900,000$ & 63 \\
log(land area) & 12.390 & 1.748 & 10.317 & 16.642 & 63 \\
Number of cities/1000 ${ }^{\text {a }}$ & 0.112 & 0.116 & 0.022 & 0.570 & 63 \\
\hline Notes: For variable definitions, see text and Data Appendix (http:www.xxx.xxx). ${ }^{\text {a }}$ Average over time.
\end{tabular}

leaves us with 24 countries covering 2,955 cities recorded at various time periods between 1980 and 2000. There are now 63 country-year pairs meaning that, on average, we observe each country 2.6 times. For the internet regressions we have to drop Mexico and restrict the time period to 1990 to 2000 . This gives us 23 countries and 41-country year pairs covering 2,792 cities. Table 1 presents the descriptive statistics of the variables used in our empirical analysis below. Additional details on our data variable definitions may be found in the online Data Appendix.

\section{Results}

We start by estimating Equation (5) for each country-year pair to get some idea of the distribution of Zipf coefficients for the countries in question. The mean Zipf coefficient across our 63 country-year pairs is -1.370 . The maximum value is -0.928 for Belarus in 1998 , the minimum is -1.714 for Belgium in 2000. Interestingly, for all country-year pairs we strongly reject the null hypothesis that the Zipf coefficient is equal to one. ${ }^{6}$ In other words, we strongly reject Zipf's law, strictly construed. See Box 1, for more details.

We now turn to consider the effect that ICT has on the city size distribution as summarized by the Zipf coefficient. As discussed in the data section, our main focus is on the

${ }^{6}$ Our result are broadly in line with those reported in Soo's 2005 table 1 which are for the last year for each country-pair and which do not implement the Gabaix-Ibragimov correction, unlike regressions along the lines of Equations (5) - (6), which do so. 


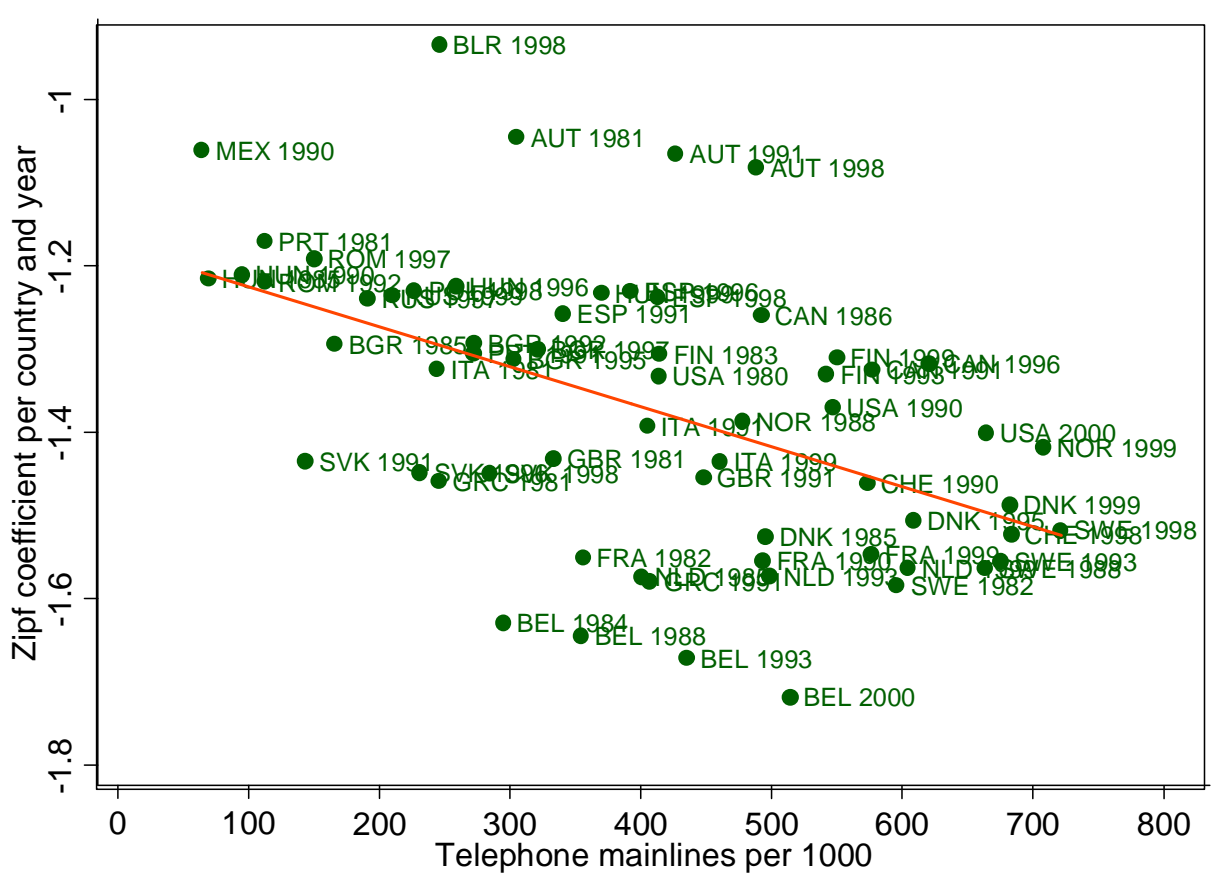

Figure 2. Estimated Zipf Coefficients against Telephone Mainlines per 1000 Inhabitants, different countries and years. Source: Authors' own calculations.

impact of phone lines. Figure 2 plots our estimates of Zipf coefficients for different countries at different times against the number of telephone lines. Two things stand out from the plot. The first is that, overall, the relationship between Zipf coefficients and the number of telephone lines is as predicted. Second, looking at individual countries, we can see the same effect replicated within the country in terms of changes over time. This is, perhaps, easiest to see for Belgium (BEL) and Austria (AUT) but careful inspection will convince the reader that a similar pattern is observed for many countries. The rest of this section formalises the findings that emerge from this scatter plot, showing that they are robust to the introduction of additional explanatory variables and to controlling for the endogeneity of telephone lines.

We begin by estimating the simplest possible specification where we treat phone lines as the only variable that explains differences in the Zipf coefficient across countries and time. That is, we estimate Equation (5) with phone lines as the only explanatory variable $\left(X_{c t}\right)$. The results are shown in column [1] of Table 2. Phone lines have a significant negative impact on the Zipf coefficient. That is, the more phone lines a country has, the more concentrated is its city size distribution. This is consistent with our theoretical result above when $\partial \gamma_{j}\left(l_{t}\right) / \partial t_{t}<0$ and $\partial \varepsilon_{j}\left(l_{t}\right) / \partial t_{t}<0$ and so improvements in ICT (or, in the data, an increase in the number of phone lines) lead to smaller local external effects and therefore a more concentrated city size distribution.

Clearly, there are many omitted characteristics of countries that could be correlated with both phone lines and the degree to which population is spread out across the city size 
Table 2: Phone lines and the city size distribution

\begin{tabular}{|c|c|c|c|c|c|c|c|c|}
\hline \multirow[b]{2}{*}{ Dep. variable $\log ($ rank- 0.5$)$} & \multicolumn{4}{|l|}{ OLS } & \multicolumn{4}{|l|}{ IV } \\
\hline & {$[1]$} & [2] & {$[3]$} & {$[4]$} & {$[5]$} & {$[6]$} & [7] & [8] \\
\hline \multicolumn{9}{|l|}{$\log ($ city size $)$} \\
\hline \multirow[t]{2}{*}{$\times \log ($ Phone lines per capita $)$} & $-0.152 * * *$ & $-0.129 * * *$ & $-0.074 * * *$ & $-0.089 * * *$ & $-0.137 * * *$ & $-0.127 * * *$ & $-0.099 * * *$ & $-0.097 * *$ \\
\hline & $(0.005)$ & $(0.010)$ & $(0.010)$ & $(0.029)$ & $(0.007)$ & $(0.029)$ & $(0.017)$ & $(0.041)$ \\
\hline \multirow[t]{2}{*}{$\times$ Inverse road density } & & $-0.290 * * *$ & & 0.181 & & $-0.224 * *$ & & 0.177 \\
\hline & & $(0.088)$ & & $(0.113)$ & & $(0.096)$ & & $(0.114)$ \\
\hline \multirow[t]{2}{*}{$\times \log ($ country population $)$} & & $-0.047 * * *$ & & -0.156 & & $-0.073 * * *$ & & -0.160 \\
\hline & & $(0.007)$ & & $(0.096)$ & & $(0.011)$ & & $(0.106)$ \\
\hline \multirow[t]{2}{*}{$\times \log ($ GDP per capita), PPP } & & $-0.083 * * *$ & & -0.065 & & -0.057 & & -0.039 \\
\hline & & $(0.023)$ & & $(0.068)$ & & $(0.039)$ & & $(0.085)$ \\
\hline \multirow[t]{2}{*}{$\times$ Trade, $\%$ GDP } & & $-0.090 * * *$ & & $0.083 * *$ & & $-0.381 * * *$ & & 0.139 \\
\hline & & $(0.017)$ & & $(0.033)$ & & $(0.070)$ & & $(0.086)$ \\
\hline \multirow[t]{2}{*}{$\times$ Non-agric. sectors, $\%$ GDP } & & -0.100 & & 0.269 & & $0.370^{*}$ & & 0.247 \\
\hline & & $(0.117)$ & & $(0.238)$ & & $(0.198)$ & & $(0.323)$ \\
\hline \multirow[t]{2}{*}{$\times$ Gov. expend., \% GDP } & & $-0.674 * * *$ & & & & $-0.517 * * *$ & & \\
\hline & & $(0.053)$ & & & & $(0.081)$ & & \\
\hline \multirow[t]{2}{*}{$\times$ Std. dev. of GDP growth } & & $-1.320 * *$ & & & & 1.532 & & \\
\hline & & $(0.618)$ & & & & $(1.051)$ & & \\
\hline \multirow[t]{2}{*}{$\times \log ($ land area $)$} & & $0.017 * * *$ & & & & 0.000 & & \\
\hline & & $(0.004)$ & & & & $(0.007)$ & & \\
\hline \multirow[t]{2}{*}{$\times$ Number of cities/1000 } & & -0.040 & & & & -0.041 & & \\
\hline & & $(0.060)$ & & & & $(0.061)$ & & \\
\hline \multirow[t]{2}{*}{$\times$ Year } & & $0.004 * * *$ & & 0.001 & & $0.004 * * *$ & & 0.001 \\
\hline & & $(0.001)$ & & $(0.002)$ & & $(0.001)$ & & $(0.003)$ \\
\hline \multirow[t]{2}{*}{$\times$ Constant } & \multirow{2}{*}{\multicolumn{4}{|c|}{$\begin{array}{l}-1.179 * * *-1.127 * * * \text { country spec. } \\
(0.006) \quad(0.008)\end{array}$}} & \multirow{3}{*}{\multicolumn{2}{|c|}{$\begin{array}{l}-1.195 * * *-1.153 * * * \\
(0.008) \quad(0.010) \\
\text { country-year spec. }\end{array}$}} & \multirow{2}{*}{\multicolumn{2}{|c|}{ country spec. }} \\
\hline & & & & & & & & \\
\hline Constant & \multicolumn{2}{|c|}{ country-year spec. } & \multicolumn{2}{|c|}{ country-year spec. } & & & \multicolumn{2}{|c|}{ country-year spec. } \\
\hline$\overline{\mathrm{R}^{2}}$ & 0.975 & 0.977 & 0.982 & 0.982 & & & & \\
\hline Obs cities & 6975 & 6975 & 6975 & 6975 & 6975 & 6975 & 6975 & 6975 \\
\hline Obs country-year & 63 & 63 & 63 & 63 & 63 & 63 & 63 & 63 \\
\hline Obs countries & 24 & 24 & 24 & 24 & 24 & 24 & 24 & 24 \\
\hline
\end{tabular}

Notes: Standard errors in brackets. ***,**, and * indicate significance at the 1\%, 5\% and $10 \%$ level, respectively. Interacted variables are mean-shifted. Instruments are dummy variables for public and private telephony monopoly, EU/EEC-, NAFTA-membership.

distribution. Column [2] begins to address this problem by including several additional explanatory variables. Before turning to discussing the empirical results, we briefly motivate each of the additional control variables.

We include the inverse of road density as a proxy for transport costs within the country. Countries with a low road density are likely to have high transport costs encouraging population to concentrate in just a few cities. Thus, we expect the coefficient on inverse road density to be positive (fewer roads imply higher inverse road density, higher transport costs and urban population that is more concentrated in fewer cities).

We include three variables to control for the economic and geographic size of the country: population, income and land area. More densely populated countries are likely to have 
more equal city size distribution, so we expect the coefficient on population to be negative while that on land area should be positive. Although we do not constrain the coefficients to be equal, these two variables could pick up other effects, thus introducing some ambiguity about the expected signs on their coefficients. Given our focus on more developed countries we have no strong prior on the sign of the coefficient on GDP. Models in the New Economic Geography tradition predict that our measure of trade openness (trade as a percentage of GDP) should have a negative effect on spatial concentration and hence on the Zipf coefficient because international trade weakens agglomeration forces (See Chapter 18 of Fujita et al., 1999). Similarly, we would expect higher agricultural production to lead to less concentration and a flatter city size distribution. That is, we expect the coefficient on non-agricultural sectors as a percentage of GDP to be positive. A measure of the size of government (government expenditure as a share of GDP) allows for the possibility that larger governments may imply higher population concentration. That would indeed be the case if (as Ades and Glaeser (1995) emphasize) rent seeking behaviour encourages citizens to locate close to policy makers in the capital city. Conversely, large governments have more means to work against agglomeration forces and support peripheral regions through regional policies. Thus we have no strong priors on the sign of the coefficient on government expenditure.

Finally, we include the standard deviation of the rate of growth of real GDP since the theory underlying our approach (discussed in Appendix A) indicates that a higher volatility of total factor productivity shocks should lead to a larger variance of the size distribution and therefore larger Zipf coefficients. We also include a time trend to capture systematic changes in the Zipf coefficient across time and the number of cities as a convenient way of allowing for non-linearities in the Zipf regression. ${ }^{7}$

Results reported in column [2] are in line with our expectations for all variables except the inverse of road density, trade as a percentage of GDP, and the volatility of GDP. Introducing country fixed effects and instrumenting for phone lines per capita alters these findings so we consider the issue no further for now. Instead, we draw attention to the fact that introducing all of these controls does not change our conclusion on the role of phone lines. The coefficient is somewhat smaller in absolute value, but still negative and highly significant. Thus, introducing a large number of additional controls does not change our conclusion that telephone lines are associated with more concentrated city size distributions.

Columns [3] and [4] of Table 2 report results after introducing a country-specific fixed effect, that is, from estimating Equation (6) rather than Equation (5). Column [3] reports results when phone lines are the only explanatory variable in $X_{c t}$. Column [4] reports re-

${ }^{7}$ Several recent studies, e.g. Black and Henderson (2003), have emphasised that the $\log$ rank - log population relationship is often concave. The relationship therefore exhibits a steep (negative) slope for the highest ranked cities and a flatter (still negative) slope for lower rank cities. Increasing the number of cities may therefore have a positive impact on the coefficient. 
sults when we include the additional control variables. Note that the coefficients for four time invariant variables cannot be identified in the fixed effect specification. These variables are time invariant either because of data availability (government expenditure as a percentage of GDP, standard deviation of GDP growth) or because they show very little time series variation (land area and number of cities). Moving from column [2] to column [3] we see that introducing unobservable country-specific effects further decreases the absolute value of the coefficient on phone lines, although the coefficient remains negative and highly significant. Introducing additional controls in column [4] leaves the effect of telephone lines per capita essentially unchanged. As mentioned above, the introduction of fixed effects now gives us signs on inverse road density and on trade as a percentage of GDP (even if the former is just insignificant) that are consistent with our theory, given a country's economic fundamentals as measured here. Thus, our finding that telephone lines are associated with more dispersed city size distributions is robust to controlling for other country characteristics both observed and unobserved.

Of course, one may still worry that the relationship is being driven by time varying unobserved characteristics of countries and that it is changes in these unobserved characteristics that drive changes in urban structure which, in turn drive changes in our explanatory variables. For example, increasing car ownership may lead to the dispersion of population and telephone lines then respond to that dispersion (rather than vice versa). To control for this, we adopt the standard solution of looking for an instrumental variable that is (i) correlated with the number of telephone lines and (ii) not in itself a determinant of the city size distribution. We construct two such variables based on the market structure in the telecommunications sector. We can identify three broad market structures for the countries in our sample: competitive, public or private monopoly. The instruments that we use are dummies for whether the country has a public monopoly or a private monopoly with a competitive structure as the excluded category. Clearly, market structure will affect the number of phone lines but it is very unlikely to be driven by the city size distribution thus satisfying the first condition for a valid instrument. In addition, we expect it to play no independent role in determining the city size distribution thus satisfying the second condition for a valid instrument.

One might have similar concerns about inverse road density as a proxy for transport costs. That is, more dispersed population leads to more roads and lower transport costs rather than transport costs driving population dispersion. We have experimented with lagged road density as an instrument but this resulted in considerable reductions in sample size and little change in the coefficient on road density. As our main interest is in the ICT variables, which we are able to instrument, we do not worry about this further other than to note that the coefficients on inverse road density should be interpreted with caution.

We have had more success with finding an instrument for trade as a percentage of GDP. Here, we use the fact that the decision to join regional trade agreements is associated with large changes in trade volumes, but surely uncorrelated with the city size distribution. Given the particular sample of countries that we consider we define two dummies, one for membership in NAFTA and a second for the membership in the EU (or EEC depending 
on time period) and use these as an instrument for trade. Finally, we assume that all other right hand side variables are exogenous.

First stage regression results are reported in Table 4. In the cross section, public monopolies decrease the number of telephone lines while private sector monopolies increase them. Once we have included a fixed effect we see that both are positively associated with the number of phone lines. Some of the time series variation in these variables comes from liberalization that moved countries from private monopolies to competition. Most of the variation, however, comes from privatization coupled with liberalization which moved countries from public monopolies to competition. ${ }^{8}$ Our results may be explained as follows. At least in terms of the number of phone lines, the efficiency effects of liberalization were outweighed by changes to public service agreements and the tendency for newly privatized firms to reduce the cross-subsidisation of residential lines by business users. In terms of the instruments for trade, entering into preferential trade agreements increases trade as expected.

Columns [5]-[8] in Table 2 show what happens when we use these variables to instrument for the number of phone lines and for trade as a percentage of GDP. Column [5] ignores country fixed effects and includes instrumented phone lines as the only explanatory variable. Comparing to column [1] we see that our results are essentially unchanged. The same is true as we introduce more explanatory variables (compare column [6] to column [2]), if we introduce fixed effects with phone lines on their own (column [7] versus column [3]) and if we introduce fixed effects and time-varying explanatory variables (column [8]). ${ }^{9}$ Comparing columns [2] and [6] illustrates that instrumenting for phone lines per capita seems to be important in assessing the effect of GDP volatility on urban structure. In column [6] we obtain that GDP volatility has a positive coefficient as the theory above predicts. The effect is very large, although very imprecisely measured since it is not significant at the $10 \%$ level.

In sum, we find a robust negative significant effect of the number of phone lines per capita on the Zipf coefficient. Over our study period, increasing phone lines per capita have tended to cause the dispersion of population resulting in a more concentrated city size distribution.

Columns [1] and [2] in Table 3 show that we reach a similar conclusion for the impact of the internet on the city size distribution. Column [1] presents results from a regression of Zipf coefficients on the number of internet users per capita. That is, from estimating equation (6) with internet users per capita as the only explanatory variable $\left(X_{c t}\right)$. We see a negative significant effect on the Zipf coefficient, although the effect is much smaller than that of phone lines. Column [2] shows what happens when we introduce the same

${ }^{8}$ During the time period we consider there were no privatisations that replace a public monopoly with a private monopoly, although this had certainly happened in earlier periods (e.g. in the United Kingdom).

${ }^{9}$ The only change is that trade as a percentage of GDP is just insignificant in the final specification (it is significant at the $10.5 \%$ level). 
Table 3: Internet users, phone lines and the city size distribution

\begin{tabular}{|c|c|c|c|c|}
\hline \multirow[b]{2}{*}{ Dep. variable $\log ($ rank-0.5) } & \multicolumn{4}{|l|}{ OLS } \\
\hline & [1] & [2] & [3] & [4] \\
\hline \multicolumn{5}{|l|}{$\log ($ city size $)$} \\
\hline \multirow[t]{2}{*}{$\times \log ($ Internet users per capita $)$} & $-0.015^{* * *}$ & $-0.025 * * *$ & \multirow{2}{*}{$\begin{array}{l}0.002 \\
(0.002)\end{array}$} & $-0.028 * * *$ \\
\hline & $(0.001)$ & $(0.004)$ & & $(0.004)$ \\
\hline \multirow[t]{2}{*}{$\times \log ($ Phone lines per capita $)$} & & & \multirow{2}{*}{$\begin{array}{l}-0.200 * * * \\
(0.009)\end{array}$} & $-0.400 * * *$ \\
\hline & & & & $(0.025)$ \\
\hline \multirow[t]{2}{*}{$\times$ Inverse road density } & & $-0.757 * * *$ & & $-0.851 * * *$ \\
\hline & & $(0.120)$ & & $(0.117)$ \\
\hline \multirow[t]{2}{*}{$\times \log ($ country population $)$} & & $-0.040 * * *$ & & $-0.096^{* * *}$ \\
\hline & & $(0.010)$ & & $(0.010)$ \\
\hline \multirow[t]{2}{*}{$\times \log ($ GDP per capita $)$, PPP } & & $-0.255^{* * *}$ & & 0.055 \\
\hline & & $(0.030)$ & & $(0.035)$ \\
\hline \multirow[t]{2}{*}{$\times$ Trade, $1 \%$ GDP } & & $-0.047 * *$ & & $0.038 *$ \\
\hline & & $(0.022)$ & & $(0.022)$ \\
\hline \multirow[t]{2}{*}{$\times$ Non-agric. sectors,$\%$ GDP } & & $0.491 * * *$ & & 0.237 \\
\hline & & $(0.158)$ & & $(0.155)$ \\
\hline \multirow[t]{2}{*}{$\times$ Gov. expend., \% GDP } & & $-0.934 * * *$ & & $-0.868 * * *$ \\
\hline & & $(0.079)$ & & $(0.077)$ \\
\hline \multirow[t]{2}{*}{$\times$ Std. dev. of GDP growth } & & $-2.959 * * *$ & & $-2.791 * * *$ \\
\hline & & $(0.921)$ & & $(0.898)$ \\
\hline \multirow[t]{2}{*}{$\times \log (\operatorname{land}$ area $)$} & & $0.023 * * *$ & & $0.061 * * *$ \\
\hline & & $(0.005)$ & & $(0.005)$ \\
\hline \multirow[t]{2}{*}{$\times$ Number of cities/1000 } & & -0.110 & & 0.007 \\
\hline & & $(0.078)$ & & $(0.077)$ \\
\hline \multirow[t]{2}{*}{$\times$ Year } & & $0.015 * * *$ & & $0.018 * * *$ \\
\hline & & $(0.002)$ & & $(0.002)$ \\
\hline \multirow[t]{2}{*}{$\times$ Constant } & $-1.342 * * *$ & $-1.245^{* * *}$ & \multirow{2}{*}{$\begin{array}{l}-1.103 * * * \\
(0.011)\end{array}$} & $-0.995 * * *$ \\
\hline & $(0.003)$ & $(0.023)$ & & $(0.027)$ \\
\hline Constant & \multicolumn{2}{|c|}{ country-year specific } & \multicolumn{2}{|c|}{ country-year specific } \\
\hline$\overline{\mathrm{R}^{2}}$ & 0.973 & 0.978 & 0.976 & \\
\hline Obs cities & 4906 & 4906 & 4906 & \\
\hline Obs country-year & 41 & 41 & 41 & \\
\hline Obs countries & 23 & 23 & 23 & \\
\hline
\end{tabular}

Notes: Standard errors in brackets. $* * *, * *$, and $*$ indicate significance at the $1 \%, 5 \%$ and $10 \%$ level, respectively. Interacted variables are mean-shifted. Instruments are dummy variables for public and private telephony monopoly, EU/EEC-, NAFTA -membership.

additional controls as we did for phone lines. If anything, introducing additional controls increases the absolute value of the coefficient on internet users per capita. Columns [3] and [4] show that the negative effect of phones and internet use is robust to considering both variables together, providing that we also include the additional controls. Results, not reported here, show that instrumenting by means of the same set of instrumental variables gives the same sign on the coefficients, but that neither are significant. The decrease in significance is particularly marked for internet usage which is not surprising given that the motivation for using market structure to instrument for internet usage is much weaker. 
That is, in many countries internet access services are provided by firms that may be unrelated to the traditional telecommunications providers. Only 16 countries have more than one year of data for internet usage so, not surprisingly, implementing the fixed effects specification gives insignificant results. We do still get the same signs for the coefficients, however. Finally, introducing fixed effects and instrumenting leads to coefficients that are essentially zero. ${ }^{10}$ This is hardly surprising given the limited number of observations and the fact that market structure in the telecommunications sector does not provide good instruments for the number of internet connections.

\subsection{Some details on instrumentation and additional robustness checks}

A careful inspection of our auxiliary results, the first-stage regressions reported in Table 4 , suggests that abolishing of public monopolies increases phone lines in the cross-section (specification [6], Table 2 and 4) and reduces phone lines in the fixed effects estimation (specification [8], Table 2 and 4). In principle there are theoretical arguments for both. However, in both cases the predicted phone lines from the first stage regressions are increasing over time. The general increase of telephone mainlines is explained by the time trend as well as increases in population, road density, and GDP. The positive sign of public and private monopolies means that abolishing these monopolies lowered the number of phones lines when it occurred (in a jump). This jump may be an extreme prediction. We therefore investigated this further by using as an additional instrument the dummy variable whether there is a public or private monopoly interacted with the time trend. This additional analysis shows that abolishing monopolies generally reduces phone lines significantly in a jump, and then is followed by slightly (but not significant) faster growth thereafter. In the respective second stage for specification [8], the effect of phone lines is even stronger, -0.106 , and now significant at $1 \%$. The trade variable now also becomes significant, although with a sign opposite to what the New Economic Geography theory would predict.

A second question concerning the nature of our instrumental variables strategy arises from considering the literature on the political economy of urbanization. This literature raises the possibility that urban concentration may be driven by the general degree of competition in the economic and political spheres. This raises the possibility that some measure of the degree of competition in the economy should be included directly in the regression, violating the second requirement for the validity of an instrument (that it should have no direct effect on urban structure). Using this line of reasoning, one could argue, for example, that the industrial organization of the telecommunications sector is actually just proxying for an overly centralized public sector which favours larger cities. To summarise, if industrial organization of the telecommunications sector is capturing other factors that have a direct effect on urban concentration, then it is inappropriate as an in-

${ }^{10}$ These results are available on request. 
Table 4: First stage regressions for Error! Reference source not found.

\begin{tabular}{|c|c|c|c|c|c|c|}
\hline \multirow[b]{2}{*}{ Dep. Variable } & \multirow{2}{*}{$\begin{array}{l}{[5]} \\
\text { log phone }\end{array}$} & \multicolumn{2}{|l|}{$[6]$} & \multirow{2}{*}{$\begin{array}{l}{[7]} \\
\text { log phone }\end{array}$} & \multicolumn{2}{|l|}{$[8]$} \\
\hline & & log phone & $\log$ trade & & log phone & $\log$ trade \\
\hline \multicolumn{7}{|l|}{$\log ($ city size $)$} \\
\hline$\times$ public monopoly & $\begin{array}{l}-0.631 \text { *** } \\
(0.013)\end{array}$ & $\begin{array}{l}-0.055^{* * *} * \\
(0.010)\end{array}$ & $\begin{array}{l}-0.073 \text { *** } \\
(0.006)\end{array}$ & $\begin{array}{l}-0.268 \text { *** } \\
(0.009)\end{array}$ & $\begin{array}{l}0.242 \text { *** } \\
(0.004)\end{array}$ & $\begin{array}{l}-0.060 * * * \\
(0.005)\end{array}$ \\
\hline$\times$ private monopoly & $\begin{array}{l}-0.285^{* * *} \\
(0.018)\end{array}$ & $\begin{array}{l}0.072 \text { *** } \\
(0.013)\end{array}$ & $\begin{array}{l}-0.053 * * * \\
(0.008)\end{array}$ & $\begin{array}{l}-0.261^{* * *} \\
(0.008)\end{array}$ & $\begin{array}{l}0.037 * * * \\
(0.004)\end{array}$ & $\begin{array}{l}-0.104 * * * \\
(0.005)\end{array}$ \\
\hline$\times \mathrm{EU}$ & $\begin{array}{l}0.159 * * * \\
(0.012)\end{array}$ & $\begin{array}{l}0.255^{* * * *} \\
(0.012)\end{array}$ & $\begin{array}{l}0.002 \\
(0.007)\end{array}$ & $\begin{array}{l}0.188^{* * * *} \\
(0.013)\end{array}$ & $\begin{array}{l}-0.210 * * * \\
(0.005)\end{array}$ & $\begin{array}{l}0.105^{* * *} \\
(0.005)\end{array}$ \\
\hline$\times$ NAFTA & $\begin{array}{l}0.332 * * * \\
(0.020)\end{array}$ & $\begin{array}{l}-0.053 * * * \\
(0.013)\end{array}$ & $\begin{array}{l}0.163 * * * \\
(0.008)\end{array}$ & $\begin{array}{l}0.196^{* * * *} \\
(0.009)\end{array}$ & $\begin{array}{l}0.003 \\
(0.007)\end{array}$ & $\begin{array}{l}0.224 * * * \\
(0.007)\end{array}$ \\
\hline$\times$ Inverse road density & & $\begin{array}{l}-1.285^{* * * *} \\
(0.098)\end{array}$ & $\begin{array}{l}0.358 * * * \\
(0.061)\end{array}$ & & $\begin{array}{l}-0.056 \\
(0.037)\end{array}$ & $\begin{array}{l}-0.035 \\
(0.041)\end{array}$ \\
\hline$\times \log ($ country population $)$ & & $\begin{array}{l}-0.305^{* * *} \\
(0.009)\end{array}$ & $\begin{array}{l}-0.090 * * * \\
(0.006)\end{array}$ & & $\begin{array}{l}-2.450 * * * \\
(0.051)\end{array}$ & $\begin{array}{c}-1.431 * * * \\
(0.056)\end{array}$ \\
\hline$\times \log ($ GDP per capita $)$, PPP & & $\begin{array}{l}1.060 * * * \\
(0.023)\end{array}$ & $\begin{array}{l}0.029 * * \\
(0.014)\end{array}$ & & $\begin{array}{l}-0.458 * * * \\
(0.022)\end{array}$ & $\begin{array}{l}-0.540 \text { **** } \\
(0.025)\end{array}$ \\
\hline$\times$ Non-agric. sectors,$\%$ GDP & & $\begin{array}{l}3.467 * * * \\
(0.125)\end{array}$ & $\begin{array}{l}2.012 * * * \\
(0.077)\end{array}$ & & $\begin{array}{l}5.302 * * * \\
(0.059)\end{array}$ & $\begin{array}{l}1.223^{* * * *} \\
(0.066)\end{array}$ \\
\hline$\times$ Gov. expend., \% GDP & & $\begin{array}{l}1.226 * * * \\
(0.056)\end{array}$ & $\begin{array}{l}0.549 * * * \\
(0.035)\end{array}$ & & & \\
\hline$\times$ Std. dev. of GDP growth & & $\begin{array}{l}18.629 * * * \\
(0.652)\end{array}$ & $\begin{array}{l}10.347 * * * \\
(0.403)\end{array}$ & & & \\
\hline$\times \log (\operatorname{land}$ area $)$ & & $\begin{array}{l}0.192 * * * \\
(0.005)\end{array}$ & $\begin{array}{l}-0.075^{* * *} \\
(0.003)\end{array}$ & & & \\
\hline$\times$ Number of cities/1000 & & $\begin{array}{l}0.557 * * * \\
(0.073)\end{array}$ & $\begin{array}{l}-0.007 \\
(0.045)\end{array}$ & & & \\
\hline$\times$ Year & & $\begin{array}{l}0.008 * * * \\
(0.001)\end{array}$ & $\begin{array}{l}-0.004^{* * * *} \\
(0.001)\end{array}$ & & $\begin{array}{l}0.055^{* * * *} \\
(0.000)\end{array}$ & $\begin{array}{l}0.012^{* * * *} \\
(0.001)\end{array}$ \\
\hline$\times$ Constant & $\begin{array}{l}0.964 * * * \\
(0.008)\end{array}$ & $\begin{array}{l}0.050 * * * \\
(0.010)\end{array}$ & $\begin{array}{l}-0.068 * * * \\
(0.006)\end{array}$ & country spe & & \\
\hline Constant & country-ye & pecific & & country-ye & pecific & \\
\hline F-Test instruments ${ }^{a}$ & 1152.0 & 257.1 & 116.5 & 920.6 & 1515.1 & 277.6 \\
\hline $\mathrm{R}^{2}$ & 0.873 & 0.966 & 0.775 & 0.979 & 0.998 & 0.953 \\
\hline Obs cities & 6975 & 6975 & 6975 & 6975 & 6975 & 6975 \\
\hline Obs country-year & 63 & 63 & 63 & 63 & 63 & 63 \\
\hline Obs countries & 24 & 24 & 24 & 24 & 24 & 24 \\
\hline
\end{tabular}

Notes: Standard errors in brackets. ***, **, and * indicate significance at the 1\%, 5\% and $10 \%$ level, respectively. Interacted variables are mean-shifted. Instruments are dummy variables for public and private telephony monopoly, EU/EEC-, NAFTA -membership.

a Jointly tests public and private telephony monopoly, EU/EEC-, NAFTA-membership.

strument. We explore this possibility by controlling for the general degree of competition in the economy using the OECD "RegRef" indicators of regulatory conditions in the airlines, telecommunications, electricity, gas, post, rail, and road freight industries of member countries (Conway and Nicoletti (2006)). The OECD claims that the RegRef indicators are a good proxy for the overall degree of competition in the economy. The RegRef indicators are, unfortunately, only available for a subset of the countries in our data set. 
Table 5: Effect of phone lines using alternative measures of urban concentration

\begin{tabular}{|c|c|c|c|c|c|c|c|c|}
\hline \multirow[b]{2}{*}{ Dep. variable } & \multicolumn{4}{|c|}{ OLS } & \multicolumn{4}{|c|}{ IV } \\
\hline & {$[1]$} & {$[2]$} & {$[3]$} & {$[4]$} & {$[5]$} & {$[6]$} & [7] & {$[8]$} \\
\hline \multicolumn{9}{|c|}{ Effect of log(Phone lines per capita), one-step estimation (Table 2) } \\
\hline \multirow[t]{2}{*}{ Zipf Coefficient } & $-0.152 * * *$ & $-0.129 * * *$ & $-0.074 * * *$ & $-0.089 * * *$ & $-0.137 * * *$ & $-0.127 * * *$ & $-0.099 * * *$ & $-0.097 * *$ \\
\hline & $(0.005)$ & $(0.010)$ & $(0.010)$ & $(0.029)$ & $(0.007)$ & $(0.029)$ & $(0.017)$ & $(0.041)$ \\
\hline \multicolumn{9}{|c|}{ Effect of log(Phone lines per capita), two-step estimation } \\
\hline \multirow[t]{2}{*}{ Zipf Coefficient } & $-0.481 * * *$ & $-0.848 * * *$ & $-0.189 * * *$ & $-0.386 * *$ & $-0.374 * *$ & -2.325 & $-0.121^{*}$ & -0.459 \\
\hline & $(0.106)$ & $(0.191)$ & $(0.046)$ & $(0.174)$ & $(0.167)$ & $(1.776)$ & $(0.069)$ & $(0.309)$ \\
\hline \multirow[t]{2}{*}{ Gini coefficient } & $-0.162 * * *$ & $-0.425 * * *$ & $-0.068 * * *$ & $-0.154 * *$ & $-0.141^{*}$ & -1.809 & $-0.055^{* *}$ & -0.106 \\
\hline & $(0.051)$ & $(0.106)$ & $(0.018)$ & $(0.062)$ & $(0.080)$ & $(1.392)$ & $(0.027)$ & $(0.119)$ \\
\hline \multirow[t]{2}{*}{ Herfindahl index } & $-0.110^{* * *}$ & $-0.212 * * *$ & $-0.032 * * *$ & -0.053 & $-0.172 * * *$ & -1.13 & -0.018 & -0.043 \\
\hline & $(0.032)$ & $(0.069)$ & $(0.009)$ & $(0.032)$ & $(0.052)$ & $(0.915)$ & $(0.013)$ & $(0.071)$ \\
\hline \multirow[t]{2}{*}{ Sample variance } & $-2.925^{* * *}$ & -0.771 & $-1.508^{*}$ & -2.26 & $-4.349 * * *$ & -6.581 & -0.272 & -4.388 \\
\hline & $(0.824)$ & $(1.601)$ & $(0.820)$ & $(2.493)$ & $(1.316)$ & $(11.698)$ & $(1.238)$ & $(6.365)$ \\
\hline Country fixed effects & no & no & yes & yes & no & no & yes & yes \\
\hline Control variables ${ }^{\text {a) }}$ & no & yes & no & yes & no & yes & no & yes \\
\hline
\end{tabular}

Notes: Standard errors in brackets. $* * *, * *$, and $*$ indicate significance at the $1 \%, 5 \%$ and $10 \%$ level, respectively.

a) Includes the same set of control variables as in Table 2.

Specifically, data are not available for Belarus, Bulgaria, Hungary, Mexico, Poland, Romania, Russian Federation, and Slovak Republic leaving 45 country-year pairs instead of the 63 pairs originally. Re-estimation of the original model with the reduced set of countries produces a stronger effect for phone lines, -0.296 , which is significant at $1 \%$. Including the average of all RegRef indicators as an additional explanatory variable only slightly reduces the effect of phone lines to -0.272 and its significance to $2 \%$. The coefficient on this new explanatory variable is close to zero and highly insignificant. Taken together these results suggest that concerns about the validity of our instrument as a result of political economy stories are theoretically interesting, but empirically invalid.

Finally, we consider what happens with other measures of urban concentration. Specifically, we have experimented with the Gini index, the normalized Herfindahl concentration index and the variance as dependent variables. These measures reflect different aspects of dispersion. The variance, a standard measure of dispersion, averages the squared deviations from the mean. The normalized Herfindahl concentration index reflects squared normalized city sizes. The Gini coefficient is the mean absolute deviation among all pairs of cities, relative to the mean city size. Results for the coefficient on telephone lines for same eight specifications (with the all controls entered without being interacted with $\ln$ (city size)) as in Table 2 are reported in Table 5. Note that all estimations using those al- 
ternative measures are based on a two-step procedure ${ }^{11}$ and therefore are less efficient than the one-step estimation in Table 2. For comparison, we therefore also report the twostep estimation using the Zipf coefficient as dependent variable. The results for the twostep using Zipf are qualitatively identical to the one-step results. Due to the loss of efficiency, they are not always significant.

Remarkably for such different measures of dispersion, the results for the coefficients of telephones line per capita with the Gini and Herfindahl indices as dependent variables are - up to a scale factor - very similar to the two-step using Zipf. The coefficients with the sample variance as a dependent variable are also negative and thus consistent with our findings using the Zipf coefficient. It is worth emphasising, however, that our choice of Zipf coefficient as a measure for urban concentration is not arbitrary, being driven instead by a desire to link our empirical results firmly with our theoretical model of urban structure. In contrast, while all three of these alternative measures of urban concentration appear intuitive, when estimated on the truncated sample of larger cities they are not consistent estimators of the population variables and cannot be linked to our theoretical prediction of decreasing variance for all cities. For this reason, the Zipf coefficient results represent our preferred specification and we take these robustness checks as broadly consistent with our overall findings.

\section{Policy Discussion and Conclusion}

We find robust evidence that increases in the number of telephone lines per capita lead to a more concentrated distribution of city sizes and so correspondingly to more dispersion in the distribution of economic activity in space. The model we presented in Section 2 rationalizes this empirical result. As access to telephones improves, the ensuing changes in city size distributions imply that local production externalities decrease. That results in an urban structure that is less dependent on past shocks and hence a size distribution of cities with smaller variance. This smaller variance is reflected in Zipf coefficients that are larger in absolute value.

Figure 3 illustrates the magnitude of our empirical results. It assumes that the size distribution of city sizes is Pareto and plots the distribution we estimate (labelled 'actual' in the figure) and the distribution we would expect if the mean of the log of phone lines per capita increases by one standard deviation. The figure also compares these two distributions with the one associated with Zipf's law, that is, a Pareto distribution with coefficient minus one, according to Equation (2). The increase in phone lines per capita concentrates the distribution, by making the Zipf relationship steeper. If ICT improves, cities are not as large. For example, the share of cities with more than a million inhabitants is reduced by two percentage points. Since the share of cities with populations larger than 1 million is

${ }^{11}$ In the first step, the measure (Zipf coefficient, Gini coefficient, Herfindahl index, sample variance) is estimated for every country and year from observed city sizes. In the second step, the measure is regressed on $\ln$ (Phone lines per capita) and control variables. 
about $10 \%$, this implies a $20 \%$ decrease in the number of these large cities. This is a significant change in urban structure!

We argue that the internet is likely to have similar, or even larger, effects on urban structures once its use has spread more thoroughly through the different economies. So far the evidence on internet usage is more speculative, although it goes in the same direction. The data suggest that as the number of internet users increases we should see effects that are about one tenth of the size of the ones we observe for phone lines. As we argue in the introduction, massive internet adoption is a fairly recent phenomenon, and at least in so far as our measurement of the extent of its adoption is concerned, urban structure may take some time to adjust. This may explain the small coefficients we find in the data.

We find that public and private monopolies on average reduce the number of phone lines per capita. An average country with a public monopoly will therefore have a more dispersed city size distribution of cities. More agents will be concentrated in a few large cities. These effects are also economically large. If the average country with a public telephone monopoly transitions to a competitive telecommunications sector, our results indicate that the change in the distribution of city sizes should be about half as large as the change in Figure 3, but in the opposite direction. That is, the Zipf curve will become flatter as the number of larger cities increases. According to our calculations above, this change would lead to an increase of around $10 \%$ in the number of cities with more than a million residents.

Even though the analysis in this paper allows us to derive conclusions about the effect of ICT on the urban structure, as it stands it is not designed to derive implications on welfare. So far we can conclude that according to the theory above, ICT causes a decrease in the strength of intra-urban spillovers. That is, ICT reduces the importance of local factors of production on the city's productivity and has led to the evolution of a more uniform distribution of cities. So far, it looks like ICT trades off spatial concentration of economic activity for total factor productivity, and thus bears a conceptual similarity to infrastructure and other regional policies, that are discussed by Martin (1999) and Baldwin et al. (2003), Ch. 17, and typically generate tradeoffs. However, increases in the scope (from urban to possibly national or international) of spillovers or factor complementarities are likely to be associated with ICT. As the scope of externalities increases, we should also expect increases in the growth rate of total factor productivity everywhere. ICT implies not only smaller local spillovers but also larger national or international spillovers. In this sense, ICT would behave more like the "win-win" policies discussed in ibid., p. 444.

This paper studies the first effect of ICT that leads to changes in the size distribution of cities. The second effect, on spillovers at a larger spatial scope, will not affect the distribution of economic activity in space, but is likely to have important implications for the growth in the mean of the distribution of total factor productivity shocks. In order to understand the welfare effects of ICT, one needs to account for both the local and national or international effects. As a first step, we have studied the local implications of ICT only.

The theory presented above implies that we can expect to see agents reallocating across cities as a result of improvements in ICT. Moreover, our empirical results imply both that the reallocation that we have observed, and that will likely observe in the future, are sub- 
stantial. Moving costs are also important and we have not commented on them so far in this paper. Some of these costs are due to regulation and lack of flexibility in labour markets. Others reflect frictions in the adjustment of urban public infrastructure. Yet other costs are due to the cost of selling and buying homes, and the actual transport and organizational costs involved in moving across cities. Our results highlight the importance of government policy in reducing this type of costs. If moving costs are artificially high, because of government regulation and interference, economies will not be able to take advantage of the gains associated with the ICT improvements, since agents will not respond by redistributing themselves accordingly in space.

It is imperative to allow for the natural reallocation that will result from further improvements in ICT. After all, this reallocation across space is the adjustment by the individuals and by firms to an economic environment where physical location is becoming less important. 


\section{REFERENCES}

Ades, Alberto F., and Edward L. Glaeser (1995), "Trade and Circuses: Explaining Urban Giants", Quarterly Journal of Economics, 110, February, 195-227.

Baldwin, Richard, Rikard Forslid, Philippe Martin, Gianmarco Ottaviano, and Frederic Robert-Nicoud (2003), Economic Geography and Public Policy, Princeton, NJ: Princeton University Press.

Black, Duncan and Vernon Henderson (2003), "Urban Evolution in the USA", Journal of Economic Geography 3(4), 343-372.

Comin, Diego A., and Bart Hobijin (2004), "Cross-Country Technological Adoption: Making the Theories Face the Facts," Journal of Monetary Economics, 39-83. Data accessible at: http://www.nber.org/hccta/.

Conway Paul and Giuseppe Nicoletti (2006), "Product Market Regulation in Non-manufacturing Sectors in OECD Countries: Measurement and Highlights", OECD Economics Department working paper 58; data accessible at: http://www.oecd.org/eco/pmr/.

Fujita, Masahisa, Paul R. Krugman and Anthony J. Venables (1999), The Spatial Economy: Cities, Regions, and International Trade, Cambridge, MA: MIT Press.

Gabaix, Xavier and Rustam Ibragimov (2006), "Log(Rank-1/2): A Simple Way to Improve the OLS Estimation of Tail Exponents", Harvard Institute of Economic Research Working Papers No. 2106.

Gabaix, Xavier and Yannis M. Ioannides (2004), 'The Evolution of City Size Distributions,' pp. 23412378, in Henderson, J. V., and J.-F. Thisse, eds., Handbook of Regional and Urban Economics, Vol. IV, Cities and Geography, Amsterdam: North-Holland.

Henderson, Vernon (1974), 'The Sizes and Types of Cities', American Economic Review, 64, March, 640-656.

Henderson, Vernon (1997), 'Medium Size Cities', Regional Science and Urban Economics, 27, 449470.

Martin, Philippe (1999), 'Public Policies, Regional Inequalities, and Growth", Journal of Public Economics, 73, 85-105.

Rosen, K. T. and M. Resnick (1980), "The Size Distribution of Cities: an Examination of the Pareto Law and Primacy", Journal of Urban Economics 8(2), 156-186.

Rossi-Hansberg, Esteban and Mark Wright (2007), "Urban Structure and Growth", Review of Economic Studies 74, April, 597-624.

Soo, Kwok Tong (2005), "Zipf's Law for Cities: a Cross-country Investigation”, Regional Science and Urban Economics 35(3), 239-263.

Zipf, George K. (1949). Human Behavior and the Principle of Least Effort. Addison-Wesley, Cambridge, MA. 


\section{APPENDIX A: A Model of ICT, Urban Evolution and City Size Distributions}

We illustrate how to study the role of ICT on the urban hierarchy by considering the basic theoretical model in RHW. Total factor productivity, that is the level of technology, in industry $j$ at time $t$ is given by

$$
\tilde{A}_{t j}=A_{t j} \tilde{H}_{t j}^{\gamma_{j}} \tilde{N}_{t j}^{\varepsilon_{j}} \text {, }
$$

where $\tilde{N}_{t j}$ and $\tilde{H}_{t j}$ denote the city's total employment and industry $j$ specific human capital, and $\ln A_{t j}$ is an independent and identically distributed (i.i.d.) productivity shock with mean zero and variance $v$. Thus parameters $\gamma_{j}$ and $\varepsilon_{j}$ determine the importance of knowledge spillovers from total employment in industry $j$ and industry $j$-specific human capital in the economy, which are external to individual firms in the industry but internal to the urban economy due to the presence of city developers. If both parameters $\gamma_{j}$ and $\varepsilon_{j}$ are equal to zero there are no external effects and economic activity has no incentive to agglomerate in cities. The larger both of these parameters the more important are a city's total human capital and employment in determining $\tilde{A}_{t j}$ city-specific total factor productivity industry $j$.

A very simple way to introduce the effect of ICT is therefore to let these two parameters vary with the quality of information technology, $\boldsymbol{l}$. Namely, let $\gamma_{j}\left(t_{t}\right)$ where $\partial \gamma_{j}\left(l_{t}\right) / \partial t_{t}<0$ and, similarly, let $\varepsilon_{j}\left(l_{t}\right)$ be such that $\partial \varepsilon_{j}\left(l_{t}\right) / \partial t_{t}<0$. Essentially, this assumption amounts to ICT's increasing the importance of agglomeration effects since people located far away can now interact at a smaller cost and so people living in the city are less important in determining the city's productivity level. Conversely, we could assume that both $\gamma_{j}\left(l_{t}\right)$ and $\varepsilon_{j}\left(l_{t}\right)$ depend positively on the quality of ICT, which would be consistent with arguments that emphasize the greater importance of public goods as a result of changes in ICT. Which effect dominates is, ultimately, an empirical question that we try to settle in this paper.

In order for city sizes to be well defined, it will be clarified shortly below that we need to guarantee that the knowledge spillover parameters $\gamma_{j}$ and $\varepsilon_{j}$ satisfy $\gamma_{j}(l)+\varepsilon_{j}(\imath)<1 / 2$ for all $\iota$. Otherwise, cities would, in a sense, be too productive and therefore would grow unboundedly since agglomeration effects would dominate congestion costs at all population levels. As long as this condition is satisfied, as a city grows eventually congestion costs become more important than agglomeration costs and so city sizes are finite.

Cities consist of a central business centre, where all agents work and all production is located, and residential areas surrounding it. Each agent consumes the services of one unit of land per period. For spatial equilibrium within each city agents should be indifferent about where to live in the city. Therefore, equilibrium rents at a distance $z$ from the centre should obey $R(z)=\tau(\bar{z}-z)$, where $\bar{z}$ denotes a city's radius, where rent is equal to 0 . Hence, total rents in a city of radius $\bar{z}$ are given by

$$
T R=\int_{0}^{\bar{z}} 2 \pi z R(z) d z=\frac{\pi \tau}{3} \bar{z}^{3}=\frac{b}{2} \tilde{N}^{\frac{3}{2}} .
$$


since everyone in the city lives in one unit of land, a city of population $\tilde{N}$ and $b \equiv 2 \pi^{-\frac{1}{2}} \tau / 3$. Total commuting costs are given by

$$
T C C=\int_{0}^{\bar{z}} 2 \pi z \tau z d z=b \tilde{N}^{\frac{3}{2}} .
$$

Assuming the presence of city developers or governments that internalize city-wide externalities, RHW show that in this framework the unique equilibrium allocation may be obtained as a solution to the following planning problem: Choose state contingent sequences $\left\{C_{t j}, X_{t j}, N_{t j}, \mu_{t j}, u_{t j}, K_{t j}, H_{t j}\right\}_{t=0, j=1}^{\infty, J}$ to maximize

$$
(1-\delta) E_{0}\left[\sum_{t=0}^{\infty} \delta^{t} N_{t}\left(\sum_{i=1}^{J} \ln C_{t i} / N_{t}\right)\right]
$$

subject to, for all $t$ and $j$,

$$
\begin{aligned}
& C_{t j}+X_{t j}+b\left(\frac{N_{t j}}{\mu_{t j}}\right)^{\frac{3}{2}} \mu_{t j} \leq A_{t j}\left(\frac{K_{t j}}{\mu_{t j}}\right)^{\beta_{j}}\left(\frac{H_{t j}}{\mu_{t j}}\right)^{\alpha_{j}+\gamma_{j}}\left(\frac{N_{t j}}{\mu_{t j}}\right)^{1-\alpha_{j}-\beta_{j}+\varepsilon_{j}} u_{t j}^{1-\alpha_{j}-\beta_{j}} \mu_{t j}, \\
& N_{t}=\sum_{j=1}^{J} N_{t j} \\
& K_{t+1 j}=K_{t j}^{\omega_{j}} X_{t j}^{1-\omega_{j}} \\
& H_{t+1 j}=H_{t j}\left[B_{j}^{0}+\left(1-u_{t j}\right) B_{j}^{1}\right],
\end{aligned}
$$

where: $N_{t j}, K_{t j}, X_{t j}$ and $H_{t j}$ denote total employment, total physical capital, physical capital investment, and total human capital in industry $j$ in the economy and $\alpha_{j}$ and $\beta_{j}$ are positive parameters satisfying $0<\alpha_{j}+\beta_{j}<1 ; C_{t j}$ denotes total consumption of representative household $i$, and $\mu_{t j}$ the number of cities producing goods in industry $j ; u_{t j}$ denotes the fraction of time agent $i$ devotes to work. Thus, the maximization problem above amounts to maximizing the sum total of households' lifetime utilities, (A.1), subject to: a resource constraint, Equation (A.2), which expresses that the use of resources for consumption, investment, and commuting costs may not exceed current output (and presupposes that rents are redistributed back to the city residents); a labour market equilibrium condition, Equation (A.3), according to which the total labour force is allocated to all industries; and the two factor accumulation equations, for physical and human capital. That is, respectively, Equation (A.4), according to which current investment and the existing capital stock produce capital stock in the next period (with $\omega_{j}$ being a parameter satisfying $0<\omega_{j}<1$ ), and Equation (A.5), where human capital is augmented at a rate that depends on the portion of each individual's endowment of leisure not allocated for work.

The problem of maximizing with respect to the number of cities $\mu_{t j}$ is a static problem with first order condition

$$
s_{t j}=\frac{N_{t j}}{\mu_{t j}}=\left[\frac{2\left(\gamma_{j}+\varepsilon_{j}\right)}{b} A_{t j} K_{t j}^{\beta_{j}} H_{t j}^{\alpha_{j}+\gamma_{j}} N_{t j}^{-\alpha_{j}-\beta_{j}+\varepsilon_{j}} u_{t j}^{1-\alpha_{j}-\beta_{j}} \mu_{t j}^{-\gamma_{j}-\varepsilon_{j}}\right]^{2} .
$$

So the size of a city, $s_{t j}$, with core industry $j$ is then given by 
$s_{t j}=\left[\left[\frac{2\left(\gamma_{j}+\varepsilon_{j}\right)}{b}\right]^{\frac{1}{1-2\left(\gamma_{j}+\varepsilon_{j}\right)}} F_{j} \hat{A}_{t j} H_{t j}^{\hat{\alpha}_{j}} K_{t j}^{\hat{\beta}_{j}} N_{t j}^{-\hat{\alpha}_{j}-\hat{\beta}_{j}} u_{t j}^{\hat{\phi}_{j}}\right]^{2}$,

where the auxiliary variables $\hat{A}_{t j}, \hat{\alpha}_{j}, \hat{\beta}_{j}$, and $\hat{\phi}_{j}$ are defined as:

$$
\begin{aligned}
& \hat{A}_{i j}=A_{t j}^{\frac{1}{1-2\left(\gamma_{j}+\varepsilon_{j}\right)}}, \hat{\alpha}_{j}=\frac{\alpha_{j}+\gamma_{j}}{1-2\left(\gamma_{j}+\varepsilon_{j}\right)}, \\
& \hat{\beta}_{j}=\frac{\beta_{j}}{1-2\left(\gamma_{j}+\varepsilon_{j}\right)}, \text { and } \hat{\phi}_{j}=\frac{1-\alpha_{j}-\beta_{j}}{1-2\left(\gamma_{j}+\varepsilon_{j}\right)} .
\end{aligned}
$$

Given this log-linear specification, RHW show that capital investments and consumption in each industry are constant fractions of output net of commuting costs, and the fraction of time devoted to work $u_{t j}$ is constant across time. Taking natural logarithms of both sides of Equation (6) that defines city size, we get

$$
\ln s_{t j}=2\left(\psi_{t j}+\frac{1}{1-2\left(\gamma_{j}+\varepsilon_{j}\right)} \ln \frac{2\left(\gamma_{j}+\varepsilon_{j}\right)}{b}+\frac{1}{1-2\left(\gamma_{j}+\varepsilon_{j}\right)} \ln A_{t j}+\hat{\beta}_{j} \ln K_{t j}\right)
$$

where the auxiliary variable $\psi_{t j}$ includes all non-stochastic variables that enter the planning problem, including $N_{t j}$ and $H_{t j}$.

If $\ln A_{t j}$ and $K_{t j}$ are the sole stochastic variables in Equation (A.7), then the mean and variance of city sizes are easily obtained and given, respectively, by

$$
\begin{aligned}
& \ln s_{t j}=2\left(\psi_{t j}+\frac{1}{1-2\left(\gamma_{j}+\varepsilon_{j}\right)} \ln \frac{2\left(\gamma_{j}+\varepsilon_{j}\right)}{b}+\hat{\beta}_{j} E\left(\ln K_{t j}\right)\right), \\
& V_{0}\left(\ln s_{t j}\right)=4\left(\frac{1}{1-2\left(\gamma_{j}+\varepsilon_{j}\right)}\right)^{2} v+4\left(\hat{\beta}_{j}\right)^{2} V\left(\ln K_{t j}\right) .
\end{aligned}
$$

It is now clear why condition $\gamma_{j}(l)+\mathcal{E}_{j}(l)<1 / 2$ must hold. They are to ensure that the mean and variance of the city size distribution are mathematically well defined. RHW show that as $t \rightarrow \infty$ the variance of the log of physical capital in industry $j$ is:

$$
V_{0}\left[\ln K_{t j}\right]=\frac{v}{\left(1+\hat{\beta}_{j}\right)^{2}},
$$

so that the variance of the long run log-city size distribution may be obtained from (A.8) and given by

$$
V_{0}\left[\ln s_{t j}\right]=4 v\left(\left(\frac{1}{1-2\left(\gamma_{j}+\varepsilon_{j}\right)}\right)^{2}+\left(\frac{\beta_{j}}{1-2\left(\gamma_{j}+\varepsilon_{j}\right)+\beta_{j}}\right)^{2}\right) .
$$

Note that the variance of the city size distribution is then increasing in $\gamma_{j}\left(l_{t}\right)+\varepsilon_{j}\left(l_{t}\right)$. Therefore, any assumption that we make about the dependence of these elasticities on ICT is reflected on changes on the invariant distribution of city sizes. 
We would also like to connect the variance of the distribution of city sizes to the Zipf's coefficient, in order to be able to connect our theoretical results with the data through this coefficient. The local Zipf coefficient is given by the elasticity of the counter-cumulative of the city size distribution, $P(s>S)$, with respect to city size,

$$
\zeta(S)=\frac{S}{P(s>S)} \frac{\partial P(s>S)}{\partial S}<0 .
$$

Given the mean of the distribution of city sizes, as we increase the variance we are shifting mass to the tails of the distribution. This implies that for $S$ high enough (large enough city sizes) the term $|\zeta(S)|$ will be smaller the larger the variance. As the variance goes to infinity, $\zeta(S)>-2, \lim _{S \rightarrow \infty} \zeta(S)$ converges to the Pareto coefficient. 


\section{CENTRE FOR ECONOMIC PERFORMANCE Recent Discussion Papers}

811 Guy Michaels

810 Maia Güell Jose V. Rodriguez Mora Chris Telmer

809 Stephen J. Redding Daniel M. Sturm Nikolaus Wolf

808 Anna Lipinska

807 Eran Yashiv

806 Ghazala Azmat Alan Manning John Van Reenen

805 Henry G. Overman Patricia Rice Anthony J. Venables

804 Benjamin Aleman-Castilla

803 Eran Yashiv

802 Nicholas Oulton

801 Mirabelle Muûls Mauro Pisu

800 Richard E. Baldwin Frédéric Robert-Nicoud

799 Alejandro Cuñat Marc J. Melitz

798 Giulia Faggio

797 Nicholas Oulton
The Division of Labor, Coordination, and the Demand for Information Processing

Intergenerational Mobility and the Informative Content of Surnames

History and Industry Location: Evidence from German Airports

The Maastricht Convergence Criteria and Optimal Monetary Policy for the EMU Accession Countries

The Beveridge Curve

Privatization, Entry Regulation and the Decline of Labor's Share of GDP: A Cross-Country Analysis of the Network Industries

Economic Linkages Across Space

The Returns to Temporary Migration to the United States: Evidence from the Mexican Urban Employment Survey

Labor Search and Matching in Macroeconomics

Jeremy Greenwood and Per Krusell, "Growth Accounting with Investment-Specific Technological Progress: A Discussion of Two Approaches" A Rejoinder

Imports and Exports at the Level of the Firm: Evidence from Belgium

Protection for Sale Made Easy

Volatility, Labor Market Flexibility, and the Pattern of Comparative Advantage

Job Destruction, Job Creation and Unemployment in Transition Countries: What Can We Learn?

Chain Indices of the Cost of Living and the PathDependence Problem: an Empirical Solution 
796 David Marsden

Richard Belfield

Salima Benhamou

795 Andrew B. Bernard

J. Bradford Jensen

Stephen Redding

Peter K. Schott

794 Richard E. Baldwin

Frédéric Robert-Nicoud

793 Alan Manning

792 Nick Bloom

791 Richard E. Baldwin

Frédéric Robert-Nicoud

790 Alan Manning

Sanchari Roy

789 Giorgio Gobbi

Roberta Zizza

788 Nick Bloom

Raffaella Sadun

John Van Reenen

787 Elizabeth O. Ananat

Guy Michaels

786 Willem H. Buiter

785 Gustavo Crespi

Chiara Criscuolo

Jonathan E. Haskel

Matthew Slaughter

784 Richard Layard

Guy Mayraz

Stephen Nickell

783 Gustavo Crespi

Chiara Criscuolo

Jonathan E. Haskel

782 Paul Castillo

Carlos Montoro

Vicente Tuesta
Inventive Pay Systems and the Management of

Human Resources in France and Great Britain

Firms in International Trade

Offshoring: General Equilibrium Effects on

Wages, Production and Trade

Respect

Uncertainty and the Dynamics of R\&D

Entry and Asymmetric Lobbying: Why

Governments Pick Losers

Culture Clash or Culture Club? The Identity and Attitudes of Immigrants in Britain

Does the Underground Economy Hold Back

Financial Deepening? Evidence from the Italian Credit Market

Americans do I.T. better: US Multinationals and the Productivity Miracle

The Effect of Marital Breakup on the Income

Distribution of Women with Children

Seigniorage

Productivity Growth, Knowledge Flows and Spillovers

The Marginal Utility of Income

Information Technology, Organisational Change and Productivity Growth: Evidence from UK Firms

Inflation Premium and Oil Price Volatility

The Centre for Economic Performance Publications Unit Tel 02079557673 Fax 02079557595 Email info@cep.lse.ac.uk Web site http://cep.lse.ac.uk 